\title{
The Geography of Housing Subsidies
}

\author{
CRED Research Paper No. 25
}

\author{
Yashar Blouri \\ University of Bern, \\ CRED
}

\author{
Simon Büchler \\ University of Bern, \\ CRED
}

\author{
Olivier Schöni \\ Laval University, \\ CRED
}

June 2019

\begin{abstract}
We investigate the spatially heterogeneous impact of the US federal mortgage interest deduction (MID) on the location and tenure decisions of households. We develop a generalequilibrium model at the county level featuring an endogenous itemization of housing subsidies. Despite being an important tax expenditure, repealing the MID would only slightly lower homeownership rates while leaving welfare mostly unchanged. The policy is ineffective because it targets locations with congested housing markets, creating a spatial shift of the housing demand toward areas that capitalize the subsidy into higher prices. We provide evidence that a repeal of the MID is to be preferred to an increase of standard tax deductions as recently implemented under President Trump's administration.
\end{abstract}

Key words: housing subsidies, residential location, tenure choice, housing supply.

JEL classification: R1, R3, H2, H3 
We are grateful to Manuel Bagues, Sascha Becker, Kristian Behrens, Maximilian von Ehrlich, David Geltner, Laurent Gobillon, Arianna Ornaghi, Albert Saiz, Tobias Seidel, Scott Wentland, and Bill Wheaton for very helpful advice and suggestions. We benefited from numerous comments at the 2019 SCSE conference in Qébec, 2019 AREUA conference in Washington, and 2019 UEA conference in Amsterdam. Support for this project from Swiss National Science Foundation with grant ref. 156186 and 181647 is gratefully acknowledged. 


\section{Introduction}

Every year, the US federal government forgoes tens of billions of tax revenue to subsidize homeownership. In 2013, the Mortgage Interest Deduction (MID) represented about $6 \%$ of the United States federal income tax revenue, that is about 98.5 billion USD. Yet this substantial tax expenditure is far from being equally distributed across the country's territory. In 2013, the average owner-occupier living in New York County (NY) received 1'813 USD in housing subsidies - about 2.13 times as much as the average owner-occupier in the US, whereas owner-occupiers of Sheridan County (WY) received an average of 222 USD per capita - about one fourth of the US average housing subsidy. In this paper, we investigate how this unequal geographic distribution of MID subsidies affects local labor and housing markets and, ultimately, welfare.

To this end, we start by developing a spatial general equilibrium model featuring the main characteristics of the US federal income tax system. In our model individuals respond endogenously to tax incentives by choosing where to live, where to work, and tenure mode. If they become owner-occupiers, they can decide whether to deduct from their taxable income a standard deduction, common to both renters and owners, or the interests paid on a mortgage loan. We calibrate our model to replicate the observed distribution of renters, owner-occupiers, commuting flows, and income across US counties. Keeping federal public expenditure constant, we find that suddenly repealing the MID would lower homeownership rates by only 0.19 percentage points, implying that the Federal Government has to forgo approximately $32^{\prime} 000$ USD of yearly income tax revenue to create a single new owner-occupier. The repeal would even slightly increase welfare by $0.01 \%$, suggesting that every year US citizens would willingly pay about 37 million USD to abandon the MID.

The slightly positive welfare effect of the repeal is the aggregate result of heterogeneous responses occurring at the local level, which are mainly given by the migration response of residents from congested housing markets to more elastic ones, by a shift of the housing demand from the owner-occupied to the rental market, and by a decrease of costly commuting flows across counties. As a result of these re-

sponses, the spatial inequality of the income distribution across counties is lowered by $0.05 \%$. When using the structure of the model to quantify the importance of 
Figure 1: County-level MID descriptives in 2013

(a) Average subsidy per homeowner

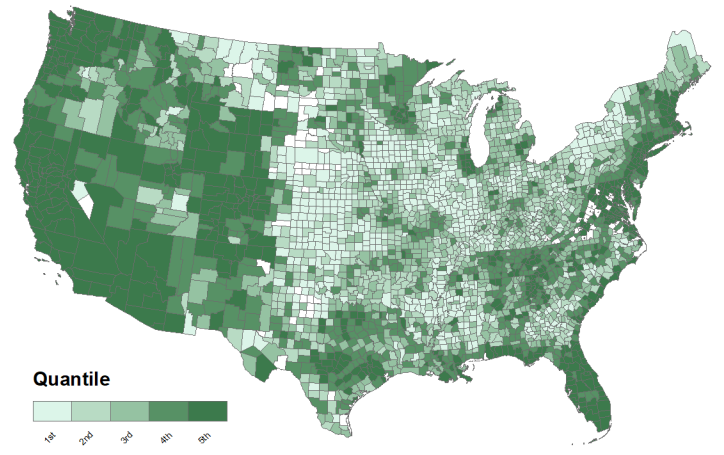

(b) Probability of itemization

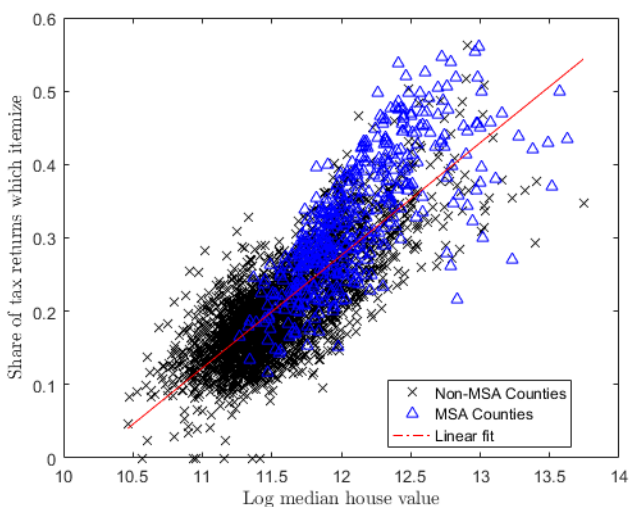

Note: Tax and MID subsidy data stem from Internal Revenue Service (IRS). Housing values provided by the American Community Survey (ACS) are averaged over 2009-2013. MSAs areas are defined according to Saiz (2010).

spatial spillovers for the migration response of renters and owner-occupiers to the repeal, we find that approximately $33 \%$ of the residents' elasticity is due to nonlocal indirect effects. These non-local effects are mostly due to the spatial linkages between locations via commuting, whereas migration and trade are less important.

In our spatial framework, we allow locations to differ in terms of productivity, housing supply elasticity, and amenities. The spatial distribution of renters and owner-occupiers is determined by the opposing effect of agglomeration and dispersion forces. The accessibility via commuting to productive locations and home markets effects lead people to concentrate in some locations, whereas housing markets and idiosyncratic tastes for location and tenure disperse them. In this baseline setting, MID subsidies counter the dispersion force of housing markets for homeowners, as they are proportional to the periodic cost of ownership. Due to commuting linkages between locations, congested housing markets of productive locations do not necessarily prevent people from working in that location and, vice versa, lowproductivity places might still attract residents. We match our model to observed data on the distribution of renters, owners, and commuting flows, as well as to estimated parameters for local housing supply elasticities, trade and commuting costs elasticities. The unique equilibrium solution of the model allows us to recover location fundamentals - productivity and individuals' taste for locations and tenure - that perfectly mimic the geographic distribution of the observed data. 
Housing supply elasticities are of particular importance in our setting, as they affect the equilibrium response of local housing markets to shifts in the housing demand. In order to analyze demand shifts between rental and onwer-occupied markets, we model two separate supply functions for these markets. This allows us to track tenure-specific equilibrium changes in the periodic costs of housing. ${ }^{1}$ Following Saiz (2010) methodology, we use US Census data on housing prices and stock changes between 1980 and 2000 to estimate housing supply elasticities at the county level. Specifically, we use housing demand shifters exogenous to the economic channels present in the structural framework to recover the shape of the housing supply function. Complementing the existing literature, we find novel evidence that county-level housing supply elasticities show important spatial variation within urban areas and between urban areas and the countryside.

Our spatial framework entails several advantages. First, it allows us to investigate a variety of tax policies affecting the way housing subsidies are distributed across US counties. As shown in Figure 1, a spatial approach seems pertinent, as the distribution of per capita MID subsidies varies considerably across locations (panel a) and itemization rates are spatially concentrated in congested housing markets displaying high housing prices (panel b). ${ }^{2}$ Existing research has mostly focused on aggregate (MSAs) areas comprising these congested markets and estimated the average effect of a homogeneous marginal change in MID subsidies. Second, the spatial linkages present in the structure of the model allow us to understand and quantify local spatial spillovers generated by the initial heterogeneous shock of the MID repeal. This quantification is important to determine the aggregate welfare response of the repeal. In that regard, empirical research has to suppose that the Stable Unit Treatment Value Assumption (SUTVA) is fulfilled to estimate the causal impact of MID subsidies, which precludes the possibility of spatial spillovers within treated areas and from treated areas to non-treated ones. ${ }^{3}$ Third, our model allows us to investigate the joint decision of where to live, where to work, and tenure mode. This

\footnotetext{
${ }^{1}$ A similar approach has been adopted by Glaeser (2008) in the case of skilled and unskilled workers consuming heterogeneous types of housing goods that are produced by separate supply functions.

${ }^{2}$ Gyourko and Sinai (2003) point out that the distribution of income-tax subsidies benefiting to owner-occupiers remains stable over time.

${ }^{3} \mathrm{~A}$ standard approach in the literature has been to use a high level of aggregation, such as MSAs, to alleviate these spatial spillovers. However, as pointed out by Monte et al. (2018), spatial linkages between locations remain important when using this level of aggregation.
} 
is a novel mechanism not explored in the existing structural literature. In the real world, we do expect individuals to react to tax incentives by adapting their location and tenure choices, thereby altering the geographic distribution of residents and workers across space.

Simulation results suggest that an unexpected MID repeal would lead to a slight welfare increase. However, such a repeal would likely be met with hostility by owneroccupiers. A legitimate question is thus whether the federal government might want to implement alternative policies to reduce the disparity in the tax treatment of renters and owner-occupiers. Despite not being its main aim, a recent example of such a policy is provided by the Tax Cuts and Jobs Act (TCJA), which was promoted by President Trump's administration and came into force in January 2018. One of the major elements of President Trump's tax reform is the doubling of the standard deduction that households (both renters and owner-occupiers) can deduct from their taxable income. ${ }^{4}$ We use the general applicability of our structural framework to evaluate the welfare impact of this increase of the standard deduction. Following President Trump's reform, we find that homeowners' MID itemization rates drop from $30.4 \%$ to $0.65 \%$ and homeownership rates decrease by 0.02 percentage points, leading to a welfare decrease of $0.05 \%$ for the whole of the country. Put differently, every year US citizens would willingly pay about 544 million USD to avoid this specific feature of the TCJA. The welfare decrease is mainly due to the subsidization of housing in the countryside, which diverts workers from productive areas.

The present paper contributes to three strands of the literature. The first strand investigates the impact of the MID on ownership attainment and various economic outcomes. ${ }^{5}$ Recent empirical research suggests that the MID is an ineffective instrument to increase homeownership. Hilber and Turner (2014) empirically show that the US federal and state MIDs capitalize into higher prices in major urban areas characterized by tightly regulated housing market, thus achieving little to improve homeownership rates. By endogenizing tenure choices and calibrating a two-region framework for Boston (MA), Binner and Day (2015) argue that it might be possible to reform the MID while leaving homeownership rates unchanged. Gruber et al.

\footnotetext{
${ }^{4}$ Some features of the reform, such as the doubling of the standard deduction, are expected to come to an end in 2025.

${ }^{5}$ See Hilber and Turner (2014) for a comprehensive review of the literature.
} 
(2017) empirically analyse a major policy reform in Denmark, which led to a substantial reduction of the MID for top-rate taxpayers. Their findings provide strong evidence that removing the subsidy mainly lowered housing prices and had no effects on homeownership attainment. Sommer and Sullivan (2018) use a dynamic macroeconomic model to show that abolishing the MID in the US would lead to a higher welfare. The equilibrium channels driving this welfare gain are lower house prices, higher homeownership rates, and lower mortgage debt.

Another strand of the literature investigates the spatial (mis)allocation of workers and the role of housing supply. Calibrating a model for US metropolitan areas, Albouy (2009) analyses the impact of the US federal income taxation on the allocation of workers across space. He persuasively shows that for a given real income, workers in high-density areas end up paying more taxes than those in more remote areas. Adopting a structural approach, Diamond (2016, 2017) investigates the link between housing supply and labor markets. In particular, these studies show that, because affecting the migration response of workers, housing supply elasticities can be exploited to identify the slope of the labor demand curve. Fajgelbaum et al. (2019) investigate how the dispersion of US state income tax rates affects the location choices of households across states. The authors show that the more pronounced the differences in income tax rates between US states are, the higher the welfare loss for the society, as workers spatially misallocate across space due to tax differentials. Hsieh and Moretti (2019) find that housing supply constraints misallocate workers by preventing them from working in productive areas, thereby hindering economic growth.

Finally, we contribute to the structural literature that investigates quantitative economic geography models by introducing several model extensions, such as households' joint decision of residential location, working place, and housing tenure. Monte et al. (2018) integrate the spatial interdependence of trade, commuting, and migration in a tractable model. Similarly, Favilukis and Van Nieuwerburgh (2018) assess the effect of out-of-town home buyers on major cities like New York in a model where heterogeneous households choose tenure and an optimal portfolio. Employing a structural framework, Blouri and Ehrlich (2019) characterize optimal regional policies that a central government can implement under budgetary constraints to 
improve welfare and reduce income inequality across locations.

The remainder of the paper is structured as follows. Section 2 presents the spatial equilibrium model. Section 3 describes the data, illustrates the estimation of county-level housing supply elasticities, and explains the counterfactual analysis. Section 4 investigates the impact of repealing the MID and analyzes the role played by spatial spillovers to determine the migration response of local residents to the repeal. Section 5 investigates the welfare implications of making MID itemization less attractive via a doubling of the standard deduction. Section 6 concludes.

\section{A Quantitative Spatial Model featuring Hous- ing Subsidies}

We consider an economy populated by a continuous measure $\bar{L}$ of workers that are distributed across $N$ locations (US counties). Extending the theoretical framework by Monte et al. (2018), each worker decides in which location $i$ to live, in which location $j$ to supply one unit of labor inelastically, and its tenure model $\omega \in\{\mathcal{O}, \mathcal{R}\}$. The federal government levies income taxes at an average rate $\tau$ and uses the collected tax revenue to provide public goods $G .{ }^{6}$ Workers earn a tenure-specific after-tax income $y_{n i}^{\omega}$ which is affected by the tax subsidies provided by the federal government.

\subsection{Households' heterogeneous preferences}

The indirect utility $V_{n i}^{\omega}(h)$ of a household $h$ living in location $n$, working in location $i$, and having a tenure mode $\omega$ is given by the following Cobb-Douglas form

$$
V_{n i}^{\omega}(h)=\frac{b_{n i}^{\omega}(h)}{\kappa_{n i}} G^{\beta}\left(\frac{y_{n i}^{\omega}}{P_{n}^{\alpha} r_{n}^{\omega 1-\alpha}}\right)^{1-\beta}
$$

where $b_{n i}^{\omega}(h)$ is an idiosyncratic taste component for a specific combination of place of residence, place of work, and tenure. We assume that the scalar utility shifter $b_{n i}^{\omega}(h)$ is the i.i.d. realization of a random variable $b_{n i}^{\omega}$ having a Fréchet distribution

\footnotetext{
${ }^{6}$ In Section D of the Appendix we extend our framework to include a progressive tax schedule and show that our main results are left unchanged.
} 
with a cumulative density function $\Omega_{n i}^{\omega}(b)=e^{-B_{n i}^{\omega} b^{-\epsilon}}$. The scale parameter $B_{n i}^{\omega}>$ 0 determines the average idiosyncratic value workers attach to a specific $n / i / \omega$ combination, whereas the shape parameter $\epsilon>1$ characterizes the taste dispersion for such a combination. The higher the value of $\epsilon$, the less dispersed the distribution of tastes.

The remaining components of the indirect utility are deterministic factors common to all workers having chosen a specific combination. The variable $\kappa_{n i}$ denotes exogenous commuting costs in terms of utility beared by workers living in location $n$ and working in $i$. Public good consumption is denoted by $G$ and real after-tax income is given by $y_{n i}^{\omega} / P_{n}^{\alpha} r_{n}^{\omega 1-\alpha}$, where $y_{n i}^{\omega}$ denotes after-tax labor income, $P_{n}$ is the price index of a basket of tradable goods, and $r_{n}^{\omega}$ is the tenure-specific cost of housing per unit of surface. The share of income spent for the composite consumption good is given by the parameter $\alpha \in[0,1]$ and $\beta \in[0,1]$ governs the workers' fondness for public good provision with respect to real after-tax income.

Each location specializes in the production of a single tradable consumption good. Workers consume a composite basket of goods $C_{n}$ according to the following CES function

$$
C_{n}=\left(\sum_{i \in N} c_{n i}^{\frac{\sigma-1}{\sigma}}\right)^{\frac{\sigma}{\sigma-1}}
$$

where $c_{n i}$ denotes the aggregate consumption in location $n$ of the good produced in $i$. The parameter $\sigma$ governs the elasticity of substitution between tradable goods. In equilibrium, we have that $c_{n i}=\alpha \bar{y}_{n} R_{n} p_{n i}^{-\sigma} P_{n}^{\sigma-1}$, where $R_{n}$ is the number of residents in location $n$ and $\bar{y}_{n}$ is location's $n$ per-capita disposable income. The price index $P_{n}$ depends on the price of individual varieties $p_{n i}$ according to $P_{n}=$

$\left[\sum_{i \in N} p_{n i}^{1-\sigma}\right]^{1 /(1-\sigma)}$. In turn, prices $p_{n i}$ equal a local price $p_{i}$, determined where the good is produced, multiplied by iceberg trade costs $d_{n i}$ between any two locations.

\subsection{Location-specific disposable income}

The amount of per capita disposable income $\bar{y}_{n}$ available in location $n$ for tradable goods and housing consumption is given by the after-tax income of households and by the redistribution of public expenditure, mortgage interests, and rental payments 
to that location. We start by describing the per capita income $y_{n i}^{\mathcal{O}}$ of owner-occupiers living in $n$ and working in $i$, which differs in three important aspects from the one of renters having chosen the same commuting pattern. First, owner-occupiers have to pay mortgage interests to the financial institution providing the mortgage loan. Second, owner-occupiers receive an additional source of income in the form of an imputed rent, which corresponds to the rent they would have to pay if they were to rent the house in which they currently live in. ${ }^{7}$ Third, owner-occupiers choose between itemizing the MID or claiming a standard tax deduction. The after-tax income of an owner-occupier is thus given by

$$
y_{n i}^{\mathcal{O}}=w_{i}-\tau\left(w_{i}-\zeta_{n i}\right)+\frac{H_{n i}^{\mathcal{O}} r_{n}^{\mathcal{O}}}{\bar{L} \lambda_{n i}^{\mathcal{O}}}-m_{n i}
$$

where

$$
\zeta_{n i}=\max \left(s, \theta m_{n i}\right)
$$

The term $w_{i}$ denotes labor income, $\tau \in[0,1]$ is the flat income tax rate set by the federal government, and $m_{n i}$ is the periodic interest paid on the mortgage loan. The income component $\frac{H_{n i}^{\mathcal{O}} r_{n}^{\mathcal{O}}}{\bar{L} \lambda_{n i}^{\mathcal{O}}}$ is the imputed rent, which depends on the share $\lambda_{n i}^{O}$ of owner-occupiers living in $n$ and working in $i$ and their corresponding aggregate housing consumption $H_{n i}^{\mathcal{O}}{ }^{8}$ The tax subsidy $\zeta_{n i}$ is affected by two exogenous parameters, the standard tax deduction $s$ and $\theta \in[0,1]$, which governs the share of MID deductible from the taxable income. We introduce this second parameter to simulate changes in the deductibility of housing subsidies. ${ }^{9}$ Because renters can only claim the standard tax deduction, their per capita disposable income is given by

$$
y_{n i}^{\mathcal{R}}=w_{i}-\tau\left(w_{i}-s\right)
$$

Note that in contrast to a standard user-cost approach, (3) is not necessarily equal to (5). This because workers' idyonsincratic preferences for location and tenure cause

\footnotetext{
${ }^{7}$ As pointed out in literature, for example by Sinai and Gyourko (2004) and Sommer et al. (2013), the non-taxation of imputed rental income represents a fiscal disincentive for owner-occupiers to become landlords and rent out their property.

${ }^{8}$ In our setting, owner-occupiers benefit from capital gains in the housing market via an increase in their imputed rental income. In Section D.1 of the Appendix we extend the model to include property taxes, which decrease imputed rental income.

${ }^{9} \mathrm{~A}$ repeal of MID subsidies, as implemented in our counterfactual simulations, corresponds to the case $\theta=0$ such that $\zeta_{n i}=$ s.
} 
frictions between the rental and owner-occupied market, thereby leading to income differentials.

We now discuss the redistributive component of location's $n$ income. We assume that public good expenditure, mortgage interests, and rental payments do not leave the economy. Rather, they accrue to a global portfolio held by a mix of federal contractors, financial institutions, and landlords. We follow Monte et al. (2018) and assume that in each location the holders of the portfolio consume tradable goods and housing proportionally to the number of residents in that location. The portfolio income $\Pi$ that a location receives for each one of its residents is given by

$$
\Pi=G+\frac{\sum_{n, i \in N}\left(\bar{L} \lambda_{n i}^{O} m_{n i}+H_{n i}^{R} r_{n}^{R}\right)}{\bar{L}},
$$

where $H_{k f}^{R}$ is the total housing consumption of renters living in $n$ and working in $i$, such that the term $\sum_{n, i \in N}\left(\bar{L} \lambda_{n i}^{O} m_{n i}+H_{n i}^{R} r_{n}^{R}\right)$ represents the total amount of mortgage interest and rental payments in the economy.

Total disposable income of region $n$ is

$$
\bar{y}_{n} R_{n}=\bar{y}_{n}^{\mathcal{O}} R_{n}^{\mathcal{O}}+\bar{y}_{n}^{\mathcal{R}} R_{n}^{\mathcal{R}},
$$

where $R_{n}^{\omega}$ is the tenure-specific number of residents. Expected disposable income $\bar{y}_{n}^{\omega}$ is given by tenure-specific income and per capita income from the global portfolio

$$
\bar{y}_{n}^{\omega}=\sum_{k \in N} \lambda_{n k \mid n}^{\omega} y_{n k}^{\omega}+\Pi,
$$

where $\lambda_{n i \mid n}^{\omega}$ is the tenure-specific share of workers residing in $n$ and working in $i$, conditional on living in $n$, i.e. $\lambda_{n i \mid n}^{\omega}=\frac{\lambda_{n i}^{\omega}}{\sum_{k} \lambda_{n k}^{\omega}} \cdot{ }^{10}$

\footnotetext{
${ }^{10}$ There are two reasons for not adding portfolio income $\Pi$ to the income $y_{n k}^{\omega}$ of renters and owneroccupiers. First, we don't want the real portfolio income to modify location and tenure choices of workers. If this were not the case, a household could decide to move to a given location to earn a higher portfolio income, which seems unrealistic. Second, according to the American Community Survey, over 2009-2013 about $81 \%$ of owner-occupiers in the US did not get any income from interests, dividends, or rental income.
} 


\subsection{Federal public good provision}

Federal tax revenue is levied on the taxable labor income of renters and owneroccupiers. Provision of the federal public good $G$ entering the utility of workers equals the per-capita tax revenue, such that

$$
G=\frac{1}{\bar{L}} \sum_{n \in N}\left(\tau \bar{L} \sum_{k \in N} \lambda_{n k}^{\mathcal{R}}\left(w_{k}-s\right)+\tau \bar{L} \sum_{k \in N} \lambda_{n k}^{\mathcal{O}}\left(w_{k}-\zeta_{n k}\right)\right)
$$

The provision of $G$ varies according to tax subsidies $s$ and $\zeta_{n k}$ that renters and owneroccupiers deduct from their wages. Higher subsidies imply a lower tax revenue and thus lower public good provision. Counterfactual simulations based on the parameters $s$ and $\theta$ are thus unable to isolate the direct income effect of housing subsidies on workers' decisions. To solve this problem, we follow Fajgelbaum et al. (2019) and allow the federal government to adjust the average income tax rate to keep the provision of the public good unaffected by changes in the subsidies. ${ }^{11}$

\subsection{Housing Markets}

Households' housing expenditure in our baseline model is tenure specific due to their idiosyncratic tastes for a given tenure mode in a specific location, and the fiscal incentive provided by housing subsidies. Given Cobb-Douglas preferences, the tenure-specific expenditure for housing of workers living in location $n$ and working in $i$ is

$$
r_{n}^{\omega} H_{n i}^{\omega}=(1-\alpha) y_{n i}^{\omega} \bar{L} \lambda_{n i}^{\omega}
$$

where $H_{n i}^{\omega}$ is the aggregate tenure-specific housing demand of workers living in $n$ and working in $i$ and $r_{n}^{\omega}$ is the periodic housing cost. The tenure-specific total housing expenditure $H_{n}^{\omega}$ in location $n$ is obtained by adding the expenditure of renters/owner-occupiers over all workplaces $i$ and by including housing consumption from the holders of the portfolio. This leads to

$$
r_{n}^{\omega} H_{n}^{\omega}=(1-\alpha) \bar{y}_{n}^{\omega} R_{n}^{\omega}
$$

\footnotetext{
${ }^{11}$ In Section C.3 of the Appendix we relax this assumption and carry out counterfactual simulations where we allow public good provision to adjust in response to a change in the housing subsidies.
} 
where the right-hand side of $(11)$ is equal to $\sum_{i}(1-\alpha)\left(y_{n i}^{\omega}+\Pi\right) \bar{L} \lambda_{n i}^{\omega}$.

Owner-occupiers subscribe mortgages with an absent financial institution charging periodic mortgage interests at an exogenous rate $\chi$ set by international capital markets. Aggregate mortgage interests of owner-occupiers living in location $n$ and working in $i$ are a constant fraction of the total owner-occupied housing value in that location

$$
\bar{L} \lambda_{n i}^{\mathcal{O}} m_{n i}=H_{n i}^{\mathcal{O}} \mathcal{P}_{n}^{\mathcal{O}} \cdot \xi \cdot \chi
$$

where $\mathcal{P}_{n}^{\omega}$ is the value of housing per unit of surface and $\xi$ is the loan-to-value ratio. ${ }^{12}$ To convert the house value $\mathcal{P}_{n}^{\omega}$ into a periodic (annual) cost $r_{n}^{\omega}$, we use the usual finite horizon present value formula $r_{n}^{\omega}=\iota \mathcal{P}_{n}^{\omega}$, where $\iota=\frac{\chi}{(1+\chi)\left(1-(1+\chi)^{-t}\right)}$ and $t$ is the lifespan of the residential unit.

We now turn to the supply side of the housing market. To analyze demand shifts between rental and owner-occupied markets, we divide the two markets by modelling two separate supply functions. This allows us to track tenure-specific equilibrium changes in the periodic costs of housing. In line with Hsieh and Moretti (2019) and Monte et al. (2018), we define tenure-specific housing supply in location $n$ as

$$
H_{n}^{\omega}=\bar{H}_{n}^{\omega} \mathcal{P}_{n}^{\omega, \eta_{n}}
$$

where $\bar{H}_{n}^{\omega}$ in an unobserved scale parameter and $\eta_{n} \in[0, \infty]$ is the local housing supply elasticity. Note that we make the simplifying assumption that the elasticity of the two markets is the same. Put differently, we allow for unobserved supply shifters contained in $\bar{H}_{n}^{\omega}$, such as housing characteristics, to affect the supply of rental and owner-occupied properties, but we restrict the relative supply responsiveness to a price shock to be the same across the two markets. The hypothesis of same responsiveness seems reasonable if we assume that factors such as regulatory and geographic constraints do not impact the supply elasticity of the two markets differently. In equilibrium, housing demand equals housing supply, leading to the

\footnotetext{
${ }^{12}$ Note that the global portfolio affects mortgage payments only via the periodic cost of owneroccupation. If this were not the case, a higher portfolio income would increase mortgage payments, which seems unrealistic.
} 
following expression

$$
r_{n}^{\omega}=\left(\frac{(1-\alpha) \bar{y}_{n}^{\omega} R_{n}^{\omega}}{\bar{H}_{n}^{\omega} \iota^{\eta_{n}}}\right)^{\frac{1}{1+\eta_{n}}}
$$

\subsection{Production}

Under perfect local competition and constant returns to scale as in Armington (1969), each location specializes in the production of one type of tradable consumption good. Production amenities of region $n$ are

$$
a_{n}=\bar{a}_{n} L_{n}^{\nu}
$$

where $\bar{a}_{n}$ is a local exogenous productivity fundamental and $L_{n}$ is the amount of workers. External agglomeration economies are captured by the parameter $\nu \geq 1$, which increases the productivity of workers. Due to this agglomeration parameter, workers supplying labor in larger labor markets are more productive, earning, ceteris paribus, higher nominal wages.

Because of the constant elasticity of substitution in (2) the aggregate value of bilateral trade flows $X_{n i}$ is

$$
X_{n i}=p_{n i} c_{n i}=\alpha \bar{y}_{n} R_{n} \frac{p_{n i}^{1-\sigma}}{P_{n}^{1-\sigma}},
$$

where profit maximizing firms cause prices to equal marginal production costs: $p_{n i}=$ $\frac{d_{n i} w_{i}}{a_{i}}$. Using these profit-maximizing prices, we can compute location's $n$ expenditure share for goods produced in location $i$

$$
\pi_{n i}=\frac{\left(\frac{d_{n i} w_{i}}{a_{i}}\right)^{1-\sigma}}{\sum_{k \in N}\left(\frac{d_{n k} w_{k}}{a_{k}}\right)^{1-\sigma}},
$$

and the corresponding price index of the composite consumption good is given by

$$
P_{n}=\left(\frac{1}{\pi_{n n}}\right)^{1 /(1-\sigma)} \frac{d_{n n} w_{n}}{a_{n}}
$$

To clear traded goods markets, location's $n$ workplace income must equal its expen- 
diture on the goods produced in that location

$$
w_{n} L_{n}=\alpha \sum_{k \in N} \pi_{k n} \bar{y}_{k} R_{k}
$$

\subsection{Labor mobility and tenure choice}

Workers are mobile and jointly choose the location $n$ where to live, the location $i$ where to work, and tenure mode $\omega$ to maximize their indirect utility $V_{n i}^{\omega}$ across all possible choices. Let $\bar{V}(h)$ denote this maximum utility level:

$$
\bar{V}(h)=\max _{n, i, \omega} V_{n i}^{\omega}(h) .
$$

As explained in Section 2.1, the stochastic nature of the indirect utility $V_{n i}^{\omega}(h)$ comes from an idiosyncratic preference term $b_{n i}^{\omega}$ that is Fréchet distributed. Because $b_{n i}^{\omega}$ shifts multiplicatively the deterministic component of $V_{n i}^{\omega}$, the indirect utility is also Fréchet distributed. We can thus write its cumulative distribution $\Psi$ as

$$
\Psi_{n i}^{\omega}(v)=e^{-\frac{B_{n i}^{\omega}}{\kappa_{n i}^{\epsilon}}\left(G^{\beta}\left(\frac{y_{n i}^{\omega}}{P_{n}^{\alpha} r_{n}^{\omega 1}}\right)^{1-\beta}\right)^{\epsilon} v^{-\epsilon}}
$$

The share of workers $\lambda_{n i}^{\omega}$ living in $n$, working in $i$, and having tenure $\omega$ is given by the probability that the utility provided by this specific combination exceeds the maximal attainable utility across all other choices, i.e. $\lambda_{n i}^{\omega}=\operatorname{Pr}\left(V_{n i}^{\omega} \geq \max _{r, k, l} V_{r k}^{l}, \forall r, k, l\right)$. Using the fact that the variable $\max _{r, k, l} V_{r k}^{l}$ is also Fréchet distributed and that $\lambda_{n i}^{\omega}=E\left[P\left(\max _{r, k, l} V_{r k}^{l} \leq v \mid V_{n i}^{\omega}=v\right)\right]$, we have that

$$
\lambda_{n i}^{\omega}=\frac{\frac{B_{n i}^{\omega}}{\kappa_{n i}^{\epsilon}}\left(G^{\beta}\left(\frac{y_{n i}^{\omega}}{P_{n}^{\alpha} r_{n}^{\omega 1-\alpha}}\right)^{1-\beta}\right)^{\epsilon}}{\sum_{k \in N} \sum_{f \in N} \sum_{l \in \omega} \frac{B_{k f}^{l}}{\kappa_{k f}^{\epsilon}}\left(G^{\beta}\left(\frac{y_{k f}^{l}}{P_{k}^{\alpha} r_{k}^{l 1-\alpha}}\right)^{1-\beta}\right)^{\epsilon}} .
$$

The parameter $\epsilon$, which governs the dispersion of idiosyncratic tastes, affects the mobility degree of workers. In the case of no taste heterogeneity across locations and tenure $(\epsilon \rightarrow \infty)$, local labor supply is perfectly elastic, implying perfect population 
mobility. The expected utility for residence $n$ and workplace $i$ is

$$
E[\bar{V}(h)]=\bar{V}=\delta\left[\sum_{k \in N} \sum_{f \in N} \sum_{l \in \omega} \frac{B_{k f}^{l}}{\kappa_{k f}^{\epsilon}}\left((G)^{\beta}\left(\frac{y_{k f}^{l}}{P_{k}^{\alpha} r_{k}^{l 1-\alpha}}\right)^{1-\beta}\right)^{\epsilon}\right]^{\frac{1}{\epsilon}}
$$

where the expectation is computed according to the distribution of idiosyncratic preferences and $\delta=\Gamma\left(\frac{\epsilon-1}{\epsilon}\right)$ is a Gamma function which depends on $\epsilon$. Inserting commuting shares (22) into expected utility for the residence and workplace combination (23) yields

$$
E\left[V_{n i}^{\omega}\right]=\delta\left(\frac{1}{\lambda_{n i}^{\omega}} \frac{B_{n i}^{\omega}}{\kappa_{n i}^{\epsilon}}\right)^{\frac{1}{\epsilon}}(G)^{\beta}\left(\frac{y_{n i}^{\omega}}{P_{n}^{\alpha} r_{n}^{\omega 1-\alpha}}\right)^{1-\beta}
$$

In equilibrium, we assume that workers do not want to change their place of residence, place of work, and tenure. This implies that the observed number of workers having chosen a specific combination must be equal to the corresponding number resulting from the distribution of idiosyncratic tastes. More precisely, summing over the probabilities across workplaces $k$, yields the number of tenure-specific residents in location $n$

$$
R_{n}^{w}=\bar{L} \sum_{k \in N} \lambda_{n k}^{w}
$$

Similarly, summing over the probabilities across place of residence $k$, yields the numbers of tenure-specific workers in location $n$

$$
L_{n}^{w}=\bar{L} \sum_{k \in N} \lambda_{k n}^{w}
$$

Finally, we ease notation and define the share of workers commuting from $n$ to $i$ as $\lambda_{n i}=\lambda_{n i}^{\mathcal{R}}+\lambda_{n i}^{\mathcal{O}}$, the total number of workers as $L_{n}=L_{n}^{\mathcal{R}}+L_{n}^{\mathcal{O}}$ and the total numbers of residents as $R_{n}=R_{n}^{\mathcal{R}}+R_{n}^{\mathcal{O}}$.

\subsection{Equilibrium characterization}

Given the set of parameters $\{\alpha, \beta, \nu, \sigma, \epsilon, \xi, \chi, s, \tau, \bar{L}\}$ and observed or estimated values for $\left\{\lambda_{n i}^{\omega}, w_{n}, r_{n}^{\omega}, \bar{y}_{n}^{\omega}, y_{n i}^{\omega}, R_{n}^{\omega}, L_{n}^{\omega}, \eta_{n}, d_{n i}\right\}$, we characterize the equilibrium of the 
baseline model with the following set of conditions. The budget of the federal government is balanced according to (9), local housing markets clear according to (14), local labor markets clear according to (17), tradable goods market clears according to (19), the price index formula is given by (18), and the spatial distribution of workers/ residents satisfies (22).

These conditions represent a system of $3 N+3 N^{2}+1$ equations, where $N$ is the number of locations (US counties), allowing us to recover the location fundamentals $\left\{a_{n}, B_{n i}^{\omega}, \pi_{n i}, G, \bar{H}_{n}^{\omega}\right\}$. All endogenous variables can be expressed in terms of these location fundamentals, exogenous variables, and parameters. ${ }^{13}$

As shown by Monte et al. (2018), this theoretical framework can be reformulated such that Allen et al. (2016) theorem can be applied to ensure the existence and uniqueness of the equilibrium.

\section{Data and estimation}

In this section, we describe the data sources available at the US county level. ${ }^{14}$ Additionally, we discuss the calibration and estimation of the exogenous parameters required to conduct counterfactual simulations. ${ }^{15}$

\subsection{Data}

Parameters provided by the literature: We set the elasticity of substitution between different varieties of tradable goods equal to $\sigma=5$, as suggested by $\mathrm{Si}$ monovska and Waugh (2014). Following Davis and Ortalo-Magne (2011) and Redding (2016), we set the share of income spent by households for consumption goods equal to $\alpha=0.7$. We set the taste dispersion parameter equal to $\epsilon=3.3$, as in Monte et al. (2018) and Bryan and Morten (2018). Following Fajgelbaum et al. (2019), the propensity to public goods consumption is given by $\beta=0.22$. The strength of the

\footnotetext{
${ }^{13}$ Section $\mathrm{C}$ of the Appendix provides further details on how to use the structure of the baseline model to perform counterfactual simulations.

${ }^{14}$ Due to data unavailability, we exclude 87 (2.8\%) out of 3143 US counties from our analysis.

${ }^{15}$ A summary of the calibrated parameters is provided in Appendix A.1. Additionally, in Appendix A.2 we present descriptive statistics and maps of exogenous and recovered variables.
} 
agglomeration force is $\nu=0.1$, as in Allen and Arkolakis (2014). Trade costs depend on the geographic distance between counties and on an average trade cost elasticity $\psi$, such that $d_{n i}^{1-\sigma}=d i s t_{n i}^{\psi}$. The former is computed using GIS data, whereas the latter is calibrated according to Monte et al. (2018), who estimate $\psi=-1.29$. We conservatively set the lifespan of a house equal to $t=40$, which corresponds to the median age of buildings according to the American Community Survey (ACS) over 2009-2013.

Housing data: Based on data published by Federal Reserve Economic Data (FRED), we set the country mortgage interest rate equal to $\chi=0.04$. This rate corresponds to the mean mortgage interest rate offered by financial institutions in 2013 for a 30-year fixed mortgage. Using the American Community Survey (ACS), we collect the share of owner-occupiers at the county level. We calibrate the loan to value ratio to $\xi=0.51$ using the balance sheet of households and nonprofit organizations provided the Financial Accounts of the Board of Governors of the Federal Reserve System (BGFRS). Specifically, we compute the LTV as the ratio of outstanding home mortgages to the value of real estate assets. Monthly rents and the value of owner-occupied houses are provided by the ACS.

Labor and income tax rates: From the Bureau of Economic Analysis (BEA) we collect data on wages by place of work and the number of employees in 2013. By dividing total wages by employment, we obtain per capita wages by workplace $w_{i}$. We use information on average federal income tax rates $\tau$ provided by the TaxSim database of the National Bureau of Economic Research (NBER) in 2013.

Commuting flows: Data on bilateral commuting flows $\lambda_{n i}$ at the county level stems from ACS for the years 2009-2013. Because the ACS does not report bilateral commutes by housing tenure, we assume identical commuting flows for owneroccupiers and renters in each county. ${ }^{16}$ We calculate tenure-choice specific commuting shares $\lambda_{n i}^{\omega}$ by multiplying the share of owner-occupiers and renters per county with the commuting flow matrix $\lambda_{n i}$.

${ }^{16}$ This hypothesis is supported by descriptive evidence provided by the ACS Micro-data on travel time by housing tenure, which suggests that, on average, renters commute daily only 1.2 minutes more than owner-occupiers, making it unlikely that their commuting flows significantly differ at the county level. 
Income and subsidy data: To obtain disposable income of renters $y_{n i}^{\mathcal{R}}$, we use (5) together with data on renters per capita wages $w_{i}$ and tax rates $\tau$. Owneroccupiers disposable income $y_{n i}^{\mathcal{O}}$ follows from (3) together with data on per-capita wages $w_{i}$, where we set $\theta=1$ in the baseline case. Next, we derive the mortgage interest rate $m_{n i}$ to finance owning properties, which follows from substituting (10) and (2.4) into (12) and data on income $y_{n i}^{\mathcal{O}}$. We substitute bilateral income $y_{n i}^{\omega}$, conditional commuting shares $\lambda_{n i \mid n}$, and the total number of workers $\bar{L}$, into (8) to recover $\bar{y}_{n}^{\omega}$. We solve for per capita expected disposable income $\bar{y}_{n}$ using (7) and the bilateral income of owner-occupiers $y_{n i}^{\mathcal{O}}$ and renters $y_{n i}^{\mathcal{R}}$. Finally, using the Internal Revenue Service (IRS) data we calibrate $s=6^{\prime} 358$ USD to ensure that the share of households that itemize in the model matches the one observed in 2013.

Recovering location fundamentals: We recover regional productivity by substituting trade shares (17) in the market clearing condition (19). Given values for $\left\{L_{n}, R_{n}, d_{n i}, w_{n}, \bar{y}_{n}\right\}$, parameter values for $\{\sigma, \alpha\}$, and estimates of $d_{n i}$, we recover productivity $a_{n}$, production amenities $\bar{a}_{n}$ and equilibrium values for bilateral trade shares. To solve for net regional consumption amenities $B_{n i}^{\omega} / \kappa_{n i}$, we substitute prices from (18) and rents (14) in commuting shares (22).

\subsection{Estimation of county-level housing supply elasticities}

Following Saiz (2010), we parsimoniously parameterize the inverse local housing supply elasticity as $\frac{1}{\eta_{n}}=\eta+\eta^{\text {built }} S_{n}^{\text {built }}$, where $S_{n}^{\text {built }}$ is the predetermined share of developed land in a given county. The parameters $\eta$ and $\eta^{\text {built }}$ represent the common and local components of the (inverse) supply responsiveness at the county level, respectively, which have to be estimated. Specifically, the interaction with the share of developed land proxies the combined effect of geographic and regulatory constraints on local supply elasticities. ${ }^{17}$

In the appendix Section B.1, we show that the inverse housing supply elasticity

\footnotetext{
${ }^{17}$ According to Hilber and Robert-Nicoud (2013), more attractive places are developed first and, as a consequence, are more tightly regulated. On the other hand, Saiz (2010) argues that geographic constraints become binding only in developed places.
} 
$\frac{1}{\eta_{n}}$ can be estimated using the following regression equation

$$
\Delta \log \mathcal{P}_{n}=\alpha+\eta \Delta \log Q_{n}+\eta^{\text {built }} S_{n}^{\text {built }} \Delta \log Q_{n}+\bar{h}_{n}^{*}
$$

where $\Delta \log \mathcal{P}_{n}$ and $\Delta \log Q_{n}$ represent price per square meter and stock growth from 1980 to 2000, respectively. ${ }^{18}$ The error term $\bar{h}_{n}^{*}$ represents unobserved price dynamics. Note that (27) exclusively exploits spatial (cross-sectional) variation to identify supply elasticity parameters, such that time dynamics are exclusively used to partial out time-invariant unobservables at the county level.

Estimating (27) by OLS likely leads to biased estimates due to the simultaneous effect of housing demand and supply in determining equilibrium prices and stock quantities. To solve this issue, we instrument changes in the housing stock $\Delta \log Q_{n}$ using exogenous demand shocks that are not modeled in our structural framework. Specifically, we predict shifts in housing demand at the county level using i) mean temperature levels in January, ii) fertility rates, and iii) a shift-share instrument for changes in the ethnic composition of residents.

We motivate the choice of instruments as follows. Counties having attractive amenities have progressively become more desirable over time, as pointed out by Glaeser et al. (2001) and Rappaport (2007). We thus expect temperature to positively correlate with an increase in demand over time. To the extent that individuals decide to live in the same county in which they are born - due for example to high idiosyncratic migration costs - predetermined fertility rates are also expected to shift housing demand upward as young adults start to bid on local housing markets, as argued by Chapelle and Eyméoud (2018). Finally, as argued by Altonji and Card (1991) and Saiz (2007), housing demand is also expected to evolve according to the (predetermined) ethnic composition of local residents. We follow and build on this proposition, and assume that the growth in local residents can be predicted by a weighted average of the growth (at the state level) of individuals belonging to a specific ethnicity, where the weights are given by the initial distribution of ethnic

\footnotetext{
${ }^{18}$ Due to limited data availability, we use the average surface of consumed housing at the region level provided by the US census to compute prices per square meter. In the appendix Section B.3, we conduct a robustness check by including additional housing characteristics measured at the county level.
} 
Table 1: County-level housing supply elasticity estimates

\begin{tabular}{|c|c|c|c|c|}
\hline \multicolumn{5}{|c|}{ Dependent variable: Growth of housing prices per $m^{2}$ between 1980 and $2000(\Delta \log \mathcal{P})$} \\
\hline \multirow[t]{2}{*}{ Instruments: } & Log-temperature & Fertility rate & $\begin{array}{l}\text { Shift-share } \\
\text { ethnicity }\end{array}$ & $\begin{array}{c}\text { All three } \\
\text { instruments }\end{array}$ \\
\hline & $(1)$ & $(2)$ & $(3)$ & $(4)$ \\
\hline$\Delta \log Q$ & $\begin{array}{l}0.685^{* * *} \\
(0.215)\end{array}$ & $\begin{array}{l}0.443^{* * *} \\
(0.144)\end{array}$ & $\begin{array}{c}0.353^{* *} \\
(0.151)\end{array}$ & $\begin{array}{l}0.444^{* * *} \\
(0.147)\end{array}$ \\
\hline$S_{n}^{\text {built }} \Delta \log Q$ & $\begin{array}{l}1.908^{* *} \\
(0.788)\end{array}$ & $\begin{array}{l}2.026^{* * *} \\
(0.715)\end{array}$ & $\begin{array}{l}1.909^{* *} \\
(0.845)\end{array}$ & $\begin{array}{l}2.088^{* *} \\
(0.815)\end{array}$ \\
\hline Observations & 3.098 & 3.098 & 3.098 & 3.098 \\
\hline Underidentification ${ }^{a}$ & 0.002 & 0.000 & 0.001 & 0.004 \\
\hline Weak identification ${ }^{\mathrm{b}}$ & 8.963 & 13.890 & 10.252 & 15.697 \\
\hline Overidentification $^{\mathrm{c}}$ & . & . & . & 0.514 \\
\hline
\end{tabular}

Note: Clustered standard errors at the state level in parentheses $* * * p<0.01,{ }^{* *} p<0.05, * p<0.1$. a) P-value of the KleibergenPaap LM statistic. b) Kleibergen-Paap F-statistic. The critical values for 10/15/20\% maximal IV size are $7.03 / 4.58 / 3.95$ in columns 1 to 3 and 26.68/12.33/9.10 in column 4, respectively. c) P-value of Hansen J statistic.

groups. $^{19}$

Median housing prices of owner-occupied housing units and total housing stock at the county level are provided by decennial US censuses and available on IPUMS (Manson et al. 2017). GIS raster data on the share of developed land comes from the "Enhanced Historical Land-Use and Land-Cover Data Sets" provided by the US Geological Survey. This data set exploits high-altitude aerial photographs collected from 1971 to $1982 .{ }^{20}$ Mean January temperature comes from the Natural Amenities Scale data published by the Department of Agriculture. County-level fertility rates, measured as live births by place of residence divided by the total population, are downloaded from IPUMS, which contains the Vital Statistics: Natality \& Mortality Data and the population decennial census data. To calculate the shift-share instrument, we use ethnicity information using census data from IPUMS.

Table 1 shows estimated values of the parameters $\eta$ and $\eta^{\text {built }}$ in (27). In columns 1 to 3 we report estimation results when using each instrument separately. Column 4 show estimation results when all three instruments are used simultaneously. As

\footnotetext{
${ }^{19}$ We use the following main ethnic groups: White, Black or African American, American Indian and Alaska Native, and Asian and Pacific Islander, and a category encompassing remaining ethnic groups. See Appendix B.2 for further computational details.

${ }^{20}$ Because the large majority of the data is collected before 1980 , we consider it predetermined with respect to our period of analysis.
} 
required by the theory, the sign of estimated parameters is positive. In particular, the higher the share of developed land in a given county, the higher $\eta_{n}$, thus resulting into a lower local housing supply elasticity. Additionally, the magnitude of the estimated coefficients is relatively stable across the instruments used to predict housing demand growth.

Using the estimates of our preferred specification (column 4 of Table 1), we compute county-level supply elasticities as $\eta_{n}=1 /\left(\eta+\eta^{\text {built }} S_{n}^{\text {built }}\right)$. We obtain supply elasticity values ranging from 0.39 (Queens county, NY) to 2.25 (Banner county, NB). In Sections B.3 and B.4 of the Appendix, we provide further evidence about the reliability of our estimates by controlling for potential supply shifters and comparing our estimates with those of Saiz (2010).

\subsection{Counterfactual analysis}

We use the theoretical framework presented in Section 2 to undertake model-based counterfactual simulations about the spatial implications of the MID. Specifically, we evaluate two alternative policies that modify how housing subsidies are allocated to individuals. With the first policy we analyze the economic impacts of suddenly repealing the MID. In the second counterfactual simulation, we investigate the general equilibrium effects of a doubling of the standard deduction, as recently implemented in the Tax Cuts and Jobs Act (TCJA) under President Trump's administration.

To quantify the welfare impact of modifying existing housing subsidies, we introduce the counterfactual 'hat' notation developed by Dekle et al. (2007) and denote

a counterfactual change as $\hat{x}=\frac{x^{\prime}}{x}$, where $x$ is the observed variable and $x^{\prime}$ its counterfactual value. To avoid modeling potentially complex changes in the allocation of public good provision by the federal government, we follow Fajgelbaum et al. (2019) and keep public good provision constant in all our counterfactual simulations. Using (24), we can then write spending-constant $(\hat{G}=1)$ counterfactual changes in US welfare as

$$
\widehat{\bar{V}}=\left(\frac{1}{\widehat{\lambda}_{n i}^{\omega}}\right)^{\frac{1}{\epsilon}}\left(\frac{\widehat{y}_{n i}^{\omega}}{\hat{P}_{n}^{\alpha} \widehat{r}_{n}^{1-\alpha}}\right)^{1-\beta}
$$

Equation (28) makes apparent that a cost-benefit analysis of modifying existing 
housing subsidies should take into account not only real income changes, but also changes in the commuting flows between local areas. A complete description of the system of equations characterizing counterfactual simulations is presented in Section C.1 of the Appendix. To provide a better intuition of our results, in what follows we separately report counterfactual changes for each one of the endogenous variables entering (28).

\section{Repealing the Mortgage Interest Deduction}

We start our analysis by investigating the welfare impacts of repealing the MID for owner-occupiers. To this end, we shock the economic system by setting $\theta=0$ in $(4) .{ }^{21}$

\subsection{Overall impact}

Table 2 shows aggregate results for the whole of the country. We compute aggregate counterfactual changes of a given welfare component by computing a weighted average of changes at the county level. The weighting scheme is adapted depending on the considered welfare component. ${ }^{22}$ Columns 1 to 3 show counterfactual results when location (place of residence and place of work) and tenure choices are kept fixed as in the baseline scenario. Keeping location and tenure choices fixed, allows us to investigate the initial income impact of repealing the MID without diving into the sorting and tenure response of individuals. In columns 4 to 6 we do allow individuals to adapt their location and tenure choices to the repeal of the subsidy. ${ }^{23}$

${ }^{21}$ In Section $\mathrm{C}$ of the Appendix we provide further details on our counterfactual simulations. In the Appendix D, we show the results of a repeal of the MID in presence of property taxes and a progressive tax schedule.

${ }^{22} \mathrm{We}$ weight using the level of the relevant outcome variable observed in the baseline scenario. Changes in commuting are weighted using baseline commuting flows, changes in residents, income, price indices, housing costs are weighted by the number of residents. Changes in wages are weighted by the number of workers.

${ }^{23}$ The baseline outcomes for the two groups of columns (1 to 3 and 4 to 6 ) are the same, which allows us to compare their changes when pertinent. Because location and tenure choices are fixed in columns 1 to 3 , thus leading to a welfare disequilibrium between renters and owner-occupiers, we do not report counterfactual changes in welfare, commuting flows, and residents for these columns. 
Table 2: Repealing the Mortgage Interest Deduction

\begin{tabular}{|c|c|c|c|c|c|c|}
\hline & \multicolumn{3}{|c|}{$\begin{array}{l}\text { Keeping location and } \\
\text { tenure choices fixed }\end{array}$} & \multicolumn{3}{|c|}{$\begin{array}{l}\text { Varying location and } \\
\text { tenure choices }\end{array}$} \\
\hline & Renters & Owners & Total & Renters & Owners & Total \\
\hline & (1) & $(2)$ & $(3)$ & $(4)$ & $(5)$ & $(6)$ \\
\hline \multicolumn{7}{|l|}{ Counterfactual changes (in \%) } \\
\hline Welfare $\left(\hat{V}_{n}\right)$ & - & - & - & 0.01 & 0.01 & 0.01 \\
\hline Commuting $\left(\sum_{n \neq i} \lambda_{n i}^{\prime} / \sum_{n \neq i} \lambda_{n i}\right)$ & - & - & - & 0.54 & -0.41 & -0.10 \\
\hline Residents $\left(\hat{R}_{n}\right)$ & - & - & - & 0.54 & -0.29 & - \\
\hline Regional income $\left(\hat{y}_{n i}\right)$ & 0.10 & -0.07 & -0.02 & 0.09 & -0.11 & -0.09 \\
\hline Wages $\left(\hat{w}_{i}\right)$ & -0.03 & -0.02 & -0.03 & -0.03 & -0.02 & -0.03 \\
\hline Housing costs $\left(\hat{r}_{n}\right)$ & 0.03 & -0.04 & -0.01 & 0.30 & -0.20 & -0.02 \\
\hline Price index $\left(\hat{P}_{n}\right)$ & -0.03 & -0.03 & -0.03 & -0.03 & -0.02 & -0.02 \\
\hline Real income $\left(\hat{y}_{n i} / \hat{P}_{n}^{\alpha} \hat{r}_{n}^{1-\alpha}\right)$ & 0.11 & -0.03 & 0.01 & 0.02 & -0.04 & -0.06 \\
\hline
\end{tabular}

In columns 1 to 3 , owner-occupiers experience a negative income shock, while renters a positive one. This because owner-occupiers that were itemizing the MID cannot do so anymore and renters are those that mostly benefit from a tax rate reduction of $1.00 \%$ following the increase in the tax revenue of the federal government. Because owner-occupiers are more numerous than renters, the overall income effect is negative. This, in turn, leads to a decrease in the consumption of tradable goods and to a corresponding decrease in wages. Housing costs also decrease (increase) for owner-occupiers (renters) following the initial income shock. The increase in housing costs for renters does not compensate the decrease in the price of tradable goods and the income increase, resulting in a real income increase.

When individuals are allowed to relocate and choose their tenure mode, repealing the MID leads to a welfare increase of $0.01 \%$. We observe a shift of the housing demand from the owner-occupied towards the rental market, as shown by the change in the number of residents reported in columns 4 and 5. In total, homeownership rate decreases by 0.19 percentage points due to the repeal. This shift of the housing demand amplifies the response of housing cost changes, leading to even higher (lower) periodic costs of renting (owning) a property. For renters, the increase in 
housing costs considerably dampens the positive real income increase, which only amounts to $0.02 \%$. The decrease in regional income of owner-occupiers outweighs the decrease in housing cost and price index, leading their real income to decrease by $0.04 \%$. Population mobility thus dilutes the real income gain experienced by renters, allowing owner-occupiers to also benefit - or limit their losses - following the repeal. ${ }^{24}$

Albeit the considerable size of the MID policy, we attribute the relatively small decline in homeownership rates to three main factors. First, in contrast to other studies, in our model workers have idiosyncratic preferences for tenure and locations, implying that they are imperfectly mobile and do not fully react to real income changes. Second, those areas in which owner-occupiers do not itemize the MID because housing values are not high enough are not affected by the repeal. Additionally, even in extremely expensive locations owner-occupiers can still claim the standard deduction. Third, in line with the reasoning of Hilber and Turner (2014), our estimated housing supply elasticities suggest that counties belonging to MSAs are fairly inelastic, thus leading to a capitalization on the subsidy in to higher housing prices.

Welfare changes presented in Table 2 draw a global portrait of the welfare consequences of repealing the MID. However, as noted before, housing subsidies are unevenly distributed across space, with high productive areas receiving most of them. This uneven distribution implies that the repeal affects some areas more than others. In that regard, it is difficult to explain changes in incoming commuting flows in Table 2 without considering the geography of the repeal. In the next section, we thus analyze how the impact of the repeal changes across space and, in particular, how it affects the location and tenure decision across MSA and countryside counties. To this end, we exclusively focus on the case with varying location and tenure choices.

\footnotetext{
${ }^{24}$ Note that because they face a unique local market price, differences in counterfactual price index changes between renters and owner-occupiers are exclusively due to differences in the weighting scheme.
} 
Figure 2: Repealing the Mortgage Interest Deduction: County-level counterfactual changes

(a) After-tax income of owner-occupiers $\left(\hat{\bar{y}}_{n}^{O}\right)$

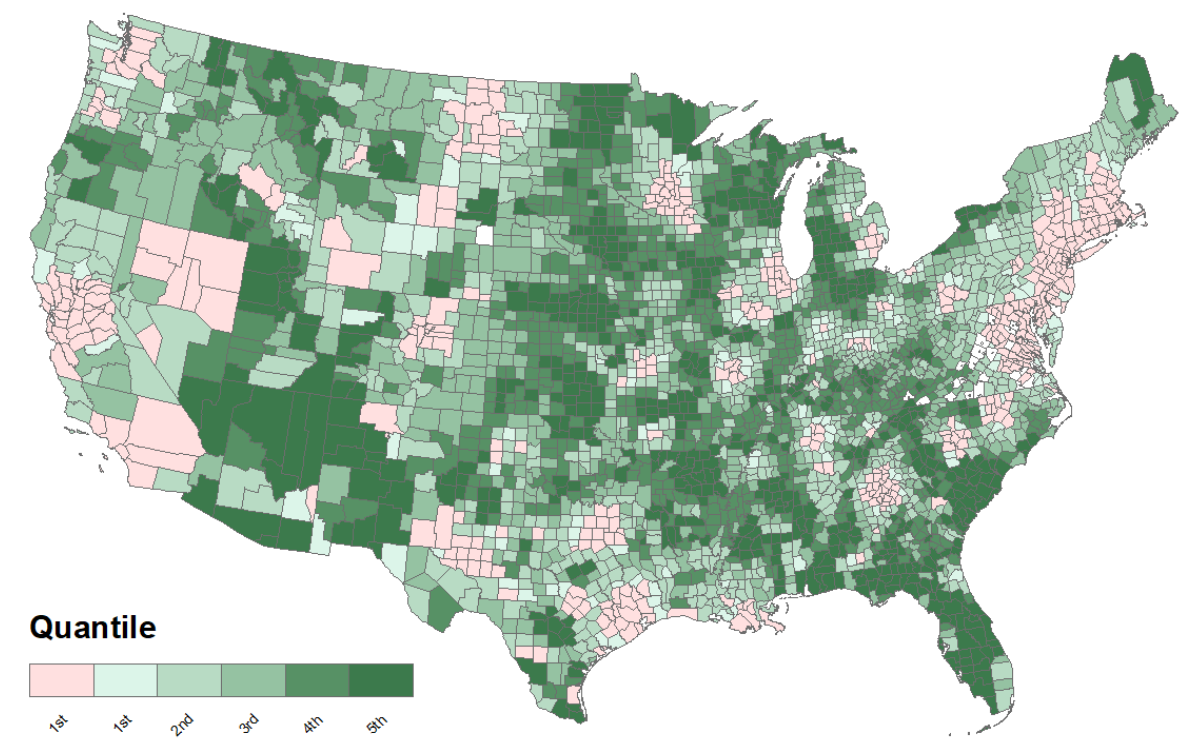

(b) Homeownership rate $\left(\hat{R}_{n}^{O} / \hat{R}_{n}\right)$

(c) Periodic cost of ownership $\left(\hat{r}_{n}^{O}\right)$
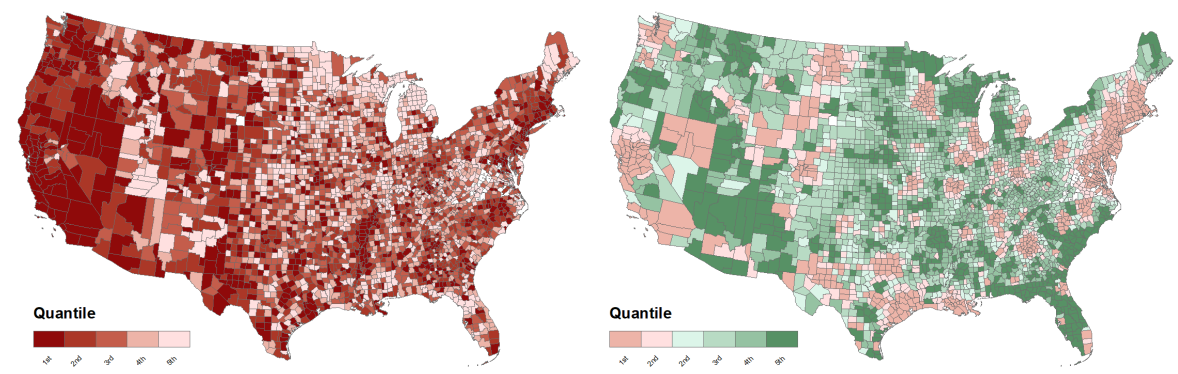

Note: We compute counterfactual changes by setting $\theta=0$. Workers can change place of residence, place of work, and tenure mode. We depict positive (negative) growth in green (red). A darker shading represents a stronger effect.

\subsection{Changes in the spatial distribution}

Figure 2 shows selected counterfactual changes that are particularly relevant for our analysis. ${ }^{25}$ As it can be seen, the negative impact of the MID repeal on the after-tax income of owner-occupiers (panel a) is mostly concentrated in MSAs such as New

${ }^{25}$ The interested reader might refer to Appendix C.2 for the full set of maps representing counterfactual changes. 
Figure 3: Repealing the MID: MSAs vs. countryside

(a) Renters

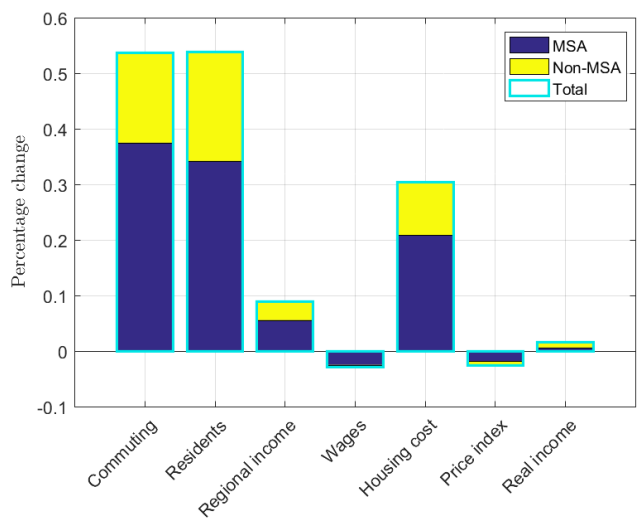

(b) Owners

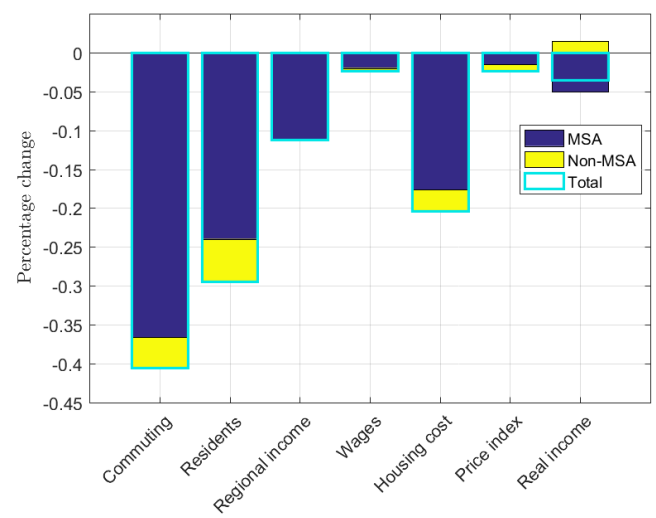

Note: We compute counterfactual changes by setting $\theta=0$. Counterfactual tax rates adjust to keep federal public expenditure fixed. The header 'owners' denotes owner-occupiers. Workers can change place of residence, place of work, and tenure mode. MSAs are defined according to Saiz (2010). County-level counterfactual changes are aggregated using weighted averages based on the distribution of outcomes in the baseline scenario. Changes in commuting are weighted by the number of commuters. Changes in residents, (real) income, rents, and prices are weighted by the number of residents. Changes in wages are weighted by the number of workers.

York, San Francisco, and Chicago. Unsurprisingly, these are the places where homeownership rates and housing prices decrease the most (panels b and c). In fact, these areas feature high MID itemization rates and low housing supply elasticities. On the contrary, as shown in panel a, onwer-occupiers in the countryside experience even a positive income shock, an effect which was masked by the aggregation scheme in Table 2. In countryside areas the decrease in homeownership rates is more contained (panel b) and is mostly due to an increase in the periodic cost of ownership (panel c) caused by a shift of the housing demand. As evident from Figure 2, the impact of the repeal strongly varies between metropolitan areas and the countryside. In what follows we thus investigate counterfactual changes across these two areas.

Figure 3 shows a stacked barplot of the impact of repealing the MID for renters (panel a) and owner-occupiers (panel b) living in counties located within and outside major urban areas. Specifically, panels (a) and (b) of Figure 3 correspond to columns 4 and 5 of Table 2, respectively. Panels (a) and (b) show that the largest part of the impacts documented in columns 4 and 5 of Table 2 are driven by MSA regions. Non-MSA areas experience, in general, the same type of welfare impact (same sign) but of lower magnitude. A notable exception to this rule is the real income of owner-occupiers, which decreases in MSA areas but increases in the countryside. We explain this opposite effect with the fact that most owner-occupiers living in 
counties located in the countryside were not itemizing the MID in the baseline specification and thus fully benefit from the income tax rate decrease following the MID repeal.

When computing the aggregate effect of panels (a) and (b) of Figure 3, counterfactulal changes for the welfare components of owner-occupiers dominate those of renters, mostly because they are more numerous. Because the MID repeal makes MSA counties which previously claimed the MID relatively less attractive compared to the baseline scenario, the aggregate effect also shows a clear shift of total residents from MSA to non-MSA areas (see Figure C.1 in the appendix). A simple analysis of concentration (Gini) indices reveals that the repeal systematically lowers spatial inequalities of income across counties by $0.05 \%$. We observe a similar reduction in spatial inequality for workers, and residents (see Table C.1 in the Appendix).

Notably, because the wage response is approximately the same for columns 1 to 3 and 4 to 6 , we argue that that increases in agglomeration economies occurring in the countryside due to the relocation of workers partially counter the loss in productivity occurring in MSAs. Indeed, renters counter the increase of rental costs by commuting over longer distances, whereas the decrease of ownership cost allows owner-occupiers to live closer to their place of work, resulting in a $0.41 \%$ decrease in commuting. Overall, commuting decreases by $0.10 \%$. Because commuting is costly in terms of welfare, this overall commuting decrease improves welfare.

\subsection{Housing subsidies and spatial spillovers}

An important body of empirical work in economics aims to quantify the causal impact of place-based policies on a variety of economic outcomes. Recently, researchers have started to raise doubts about the reliability of empirical estimates describing the (average) treatment effect of place-based policies due to a potential violation of the Stable Unit Treatment Value Assumption (SUTVA). ${ }^{26}$ Questioning the validity of the SUTVA seems natural when investigating policies affecting determined areas due to the spatial linkages between regions. In fact, these linkages might create spatial spillovers from treated to non-treated areas and from treated areas to other

\footnotetext{
${ }^{26}$ See Baum-Snow and Ferreira (2015) for a comprehensive review of the issue.
} 
treated areas, thus biasing treatment effect estimates.

As discussed in the previous sections, MID subsidies are itemized, on average, only in places with congested housing markets displaying high housing costs. Moreover, housing subsidies are usually unequally distributed across itemizing areas, creating heterogeneous treatment effects. Virtually all studies aiming to quantify the impacts of housing subsidies across space rely on empirical analyses exploiting this variation in the magnitude of the subsidies among recipient regions. However, the aggregate efficiency of spatially targeted housing subsidies critically depends on migration and commuting responses, the shift between rental and owner-occupied demand, and local prices in general. Ignoring the spatial spillovers of the subsidies to other regions amounts to quantifying partial equilibrium effects. ${ }^{27}$ In our structural model, spatial spillovers take the form of complex general equilibrium responses through labor mobility and trade linkages. Because we calibrate labor mobility with real-world patterns, these spillovers are not necessarily limited to neighboring regions.

In this section, we suggest a model-based strategy allowing to quantify the magnitude of spatial spillovers for residential location choices and thus, indirectly, to determine whether they represent a sizable limitation of empirical studies. ${ }^{28}$ To this end, in a first step we formalize the general equilibrium elasticity of local residents to housing subsidies. In a second step, we disentangle the impact of local and non-local effects (spatial spillover) on this elasticity.

\footnotetext{
${ }^{27}$ Some empirical studies try to alleviate the issue of spatial spillovers by excluding observations in the immediate proximity of treated regions from the control group. From a general equilibrium perspective, this is unsatisfactory for two reasons. First, spatial linkages are not necessarily limited to neighboring areas. Second, spillovers also occur within treated areas.

${ }^{28}$ A similar analysis can be performed for the elasticity of other outcomes. We focus on the elasticity of local residents because of its relevance for the policy we analyze.
} 


\subsubsection{Understanding residential location choices}

Let $\gamma^{R_{n}^{\omega}, \theta}=\frac{d R_{n}^{\omega}}{d \theta} \frac{\theta}{R_{n}^{\omega}}$ denote the tenure-specific elasticity of local residents to housing subsidies. By computing the total derivative of (25) with respect to $\theta$, we have

$$
\begin{aligned}
\gamma^{R_{n}^{\omega}, \theta} & =(1-\beta) \epsilon\left(\sum_{k \in N} \frac{\bar{L}^{\omega} \lambda_{n k}^{\omega}}{R_{n}^{\omega}} \gamma^{\gamma_{n k}^{\omega}, \theta}-\sum_{k \in N} \sum_{f \in N} \lambda_{k f}^{\omega} \gamma^{\omega_{k f}^{\omega}, \theta}\right) \\
& -(1-\beta) \epsilon \alpha\left(\gamma^{P_{n}, \theta}-\sum_{k \in N} \frac{R_{k}^{\omega}}{\bar{L}^{\omega}} \gamma^{P_{k}, \theta}\right) \\
& -(1-\beta) \epsilon(1-\alpha)\left(\gamma^{r_{n}^{\omega}, \theta}-\sum_{k \in N} \frac{R_{k}^{\omega}}{\bar{L}^{\omega}} \gamma^{r_{k}^{\omega}, \theta}\right)+\gamma^{\bar{L}^{\omega}, \theta}
\end{aligned}
$$

where $\gamma^{,}, \theta$ denotes the elasticity of a given variable with respect to housing subsidies.

Equation (29) tells us that the relative change in the spatial distribution of residents due to a relative change in housing subsidies is determined by three main channels. The first channel is the income response to the subsidy. The second and third channels describe the relationship between housing subsidies and the price of tradable goods and housing costs, respectively. ${ }^{29}$

The first term within the large parentheses always represents a change in the local attractiveness of a location with respect to income, tradable goods prices, and housing costs. The second term within the parentheses relates to a counterfactual change in the attractiveness of all other locations, as their income and prices also change. Put differently, residents in $n$ might react to changes in housing subsidies even if location $n$ is not directly affected by the repeal, but its relative attractiveness is. As such, even in counties where owners do not itemize the MID, the elasticity of residents might be different from to zero due to spatial spillovers. A few remarks are worth noting. First, each of the channels in (29) is tenure specific and, as such, can have opposite sign across tenure.

Second, a crucial role in the change of residents is played by the taste dispersion $\epsilon$ and the share of private expenditure $1-\beta$. Both parameters govern the degree of mobility of people, affecting their responsiveness to housing subsidies. For example,

\footnotetext{
${ }^{29}$ As before, we assume that the federal government adjusts tax rates to keep public good provision constant, such that the elasticity of public goods to housing subsidies is identically zero.
} 
when $\epsilon \rightarrow 1$, individual taste is all that matters and residents do not respond to housing subsidies. When $\epsilon$ is higher, people are sensitive to a change in the subsidy. In a similar vein, the more people care about real income over public good provision, the stronger the incentives to relocate according to housing subsidies.

Third, the magnitude of the elasticities $\gamma^{,}, \theta$ depends on exogenous location characteristics. For example, the income elasticity $\gamma^{y_{n k}^{\omega}, \theta}$ is expected to be positive and large in magnitude in highly productive places located in MSA areas, which typically have congested housing markets. Similarly, changes in consumption prices $\gamma^{P_{n}, \theta}$ are linked to trade costs. The housing cost response to housing subsidies $\gamma^{r_{n}^{\omega}, \theta}$ depends on local housing supply elasticities.

\subsubsection{Quantifying the importance of spatial spillovers}

As shown by (29), the elasticity of local residents in county $n$ is composed of local effects - originating from elasticities where $k=n$, i.e. $\gamma^{y_{n n}^{\omega}, \theta}, \gamma^{P_{n}, \theta}$ and $\gamma^{r_{n}^{\omega}, \theta}$ and non-local effects that arise from elasticities in other locations, where $k \neq n$, namely $\gamma^{y_{n k}^{\omega}, \theta}, \gamma^{P_{k}, \theta}$ and $\gamma_{k}^{r_{k}^{\omega}, \theta}$. We use this distinction to separately quantify the role played by local and non-local income, consumption prices, and housing cost effects in the determination of local resident elasticities with respect to housing subsidies. Specifically, we investigate how much of the observed spatial variation of local resident elasticities is explained by local and non-local effects.

Specifically, we quantify local resident elasticities and the corresponding local and non-local components of (29) by simulating the MID repeal of Section 4. In a second step, we perform a Shorrocks-Shapley decomposition by regressing local resident elasticities on all possible combinations of the elasticity components and computing the corresponding $R^{2}$ for each combination. For each component, we then calculate the average improvement of the $R^{2}$ when adding that component as a covariate to the regression. This average improvement is interpreted as the relative importance of the component to explain the variation in the elasticity of residents. Table 3 shows the results.

Panel A of Table 3 evaluates the overall importance of local and non-local channels for renters and owner-occupiers, without distinguishing which endogenous chan- 
Table 3: Importance of spatial spillovers for residents' elasticity

\begin{tabular}{lccc}
\hline & & $\begin{array}{c}\text { Renters } \\
(1)\end{array}$ & $\begin{array}{c}\text { Owners } \\
(2)\end{array}$ \\
\hline Panel A: All channels & local & 0.68 & 0.67 \\
& non-local & 0.32 & 0.33 \\
\hline Total $^{\mathrm{a}}$ & & 1 & 1 \\
& & & \\
Panel B: Individual channels & local & 0.33 & 0.36 \\
\hline Income & non-local & 0.21 & 0.18 \\
Income & local & 0.14 & 0.03 \\
Price index & non-local & 0.03 & 0.03 \\
Price index & local & 0.25 & 0.33 \\
Housing costs & non-local & 0.05 & 0.07 \\
Housing costs & & 1 & 1 \\
\hline Total & & &
\end{tabular}

Note: We compute counterfactual changes by setting $\theta=0$. The header 'owners' denotes owner-occupiers. The reported values correspond to the contribution of a given channel in a Shorrocks-Shapley decomposition of the residents' elasticity. ${ }^{a}$ Because (29) is an analytical relationship, linearly regressing local resident elasticities on the full set of components leads to a perfect fit.

nel responds to the subsidies. Our results suggest that $32 \%$ and $33 \%$ of the observed spatial variation in the elasticity of renters and owner-occupiers is due to responses having occurred in other areas, respectively. When assessing the relative importance of local and non-local effects for each channel entering (29), as shown in panel B, we find that income and housing costs represent the most important channels affecting the residential elasticities of renters and owner-occupiers, whereas the price index of tradable goods only plays a minor role. A good part of the importance of the income channel comes from non-local effects stemming from spatial linkages of the labor market via commuting flows. On the contrary, non-local effects do not represent a major component of the housing costs channel, implying that the migration response of residents is mostly affected when housing subsidies directly affect local housing markets.

These results seem to suggest that spatial spillovers are an important component of local elasticities of renters and owner-occupiers to housing subsidies. This importance highlights potential shortcomings of empirical analyses aiming to quantify the causal impact of the MID on economic outcomes and welfare. 


\section{$5 \quad$ Making MID itemization less attractive}

Up to now we have concerned ourselves with the evaluation of the welfare impact of repealing the MID. Despite a repeal seems to be beneficial for the country, it would likely be met with hostility by voters and owner-occupiers in particular. A legitimate question is thus whether a government that aims to reduce the disparity in the tax treatment between renters and owner-occupiers can overcome this hostility by implementing a policy that makes MID itemization less attractive.

Despite not being its main purpose, a recent example of such a policy is provided by the TCJA, which was promoted by President Trump's administration and came into force in January 2018. One of the major elements of this tax reform is the doubling of the standard deduction that households can deduct from their taxable income. ${ }^{30}$ The areas that benefit the most from the increase in the standard deduction in real terms are those located in the countryside, where President Trump's received most votes during the 2016 US presidential election. Unsurprisingly, most pundits expect an important drop in MID itemization rates.

In this section, we thus investigate the welfare impact of doubling the standard deduction $s .{ }^{31}$ As in the previous section, we adjust income tax rates to keep federal public good provision constant.

\subsection{Overall impact}

Table 4 shows the simulation results when doubling the calibrated value of the standard deduction $s$ - which increases from 6'358 USD to $12^{\prime} 717$ USD - in (4). Columns 1 to 3 show the impact of the tax reform when individuals cannot adapt location and tenure choices in response to the increase of the standard deduction, whereas in columns 4 to 6 we allow for such a response.

\footnotetext{
${ }^{30}$ Other key elements of the tax reform are reductions in tax rates for businesses and individuals, family tax credits, limiting deductions for state and local income taxes (SALT) and property taxes, reducing the alternative minimum tax for individuals and eliminating it for corporations, reducing the number of estates impacted by the estate tax, and repealing the individual mandate of the Affordable Care Act.

${ }^{31}$ Despite our model is calibrated with 2013 data, changes in the tax system between 2013 and 2017 have been minor.
} 
Table 4: Doubling the standard deduction

\begin{tabular}{|c|c|c|c|c|c|c|}
\hline & \multicolumn{3}{|c|}{$\begin{array}{l}\text { Keeping location and } \\
\text { tenure choices fixed }\end{array}$} & \multicolumn{3}{|c|}{$\begin{array}{l}\text { Varying location and } \\
\text { tenure choices }\end{array}$} \\
\hline & Renters & Owners & Total & Renters & Owners & Total \\
\hline & $(1)$ & $(2)$ & $(3)$ & $(4)$ & $(5)$ & $(6)$ \\
\hline \multicolumn{7}{|l|}{ Counterfactual changes (in \%) } \\
\hline Welfare $\left(\hat{V}_{n}\right)$ & - & - & - & -0.05 & -0.05 & -0.05 \\
\hline Commuting $\left(\sum_{n \neq i} \lambda_{n i}^{\prime} / \sum_{n \neq i} \lambda_{n i}\right)$ & - & - & - & -0.17 & -0.38 & -0.31 \\
\hline Residents $\left(\hat{R}_{n}\right)$ & - & - & - & 0.05 & -0.03 & - \\
\hline Regional income $\left(\hat{y}_{n i}\right)$ & -0.05 & -0.07 & -0.07 & -0.28 & -0.34 & -0.34 \\
\hline Wages $\left(\hat{w}_{i}\right)$ & -0.20 & -0.15 & -0.17 & -0.12 & -0.09 & -0.10 \\
\hline Housing costs $\left(\hat{r}_{n}\right)$ & -0.10 & -0.10 & -0.10 & -0.18 & -0.25 & -0.23 \\
\hline Price index $\left(\hat{P}_{n}\right)$ & -0.21 & -0.18 & -0.19 & -0.09 & -0.09 & -0.09 \\
\hline Real income $\left(\hat{y}_{n i} / \hat{P}_{n}^{\alpha} \hat{r}_{n}^{1-\alpha}\right)$ & 0.13 & 0.08 & 0.09 & -0.16 & -0.20 & -0.21 \\
\hline
\end{tabular}

In our simulations the share of owner-occupiers itemizing the MID drops from $30.4 \%$ to $0.65 \%$ after the tax reform comes into force, with only counties having highly congested housing markets continuing to claim the deduction. Doubling the standard deduction considerably decreases the tax revenue of the federal government, which to keep public good provision constant is forced to increase income tax rates. This increase in tax rates negatively affects the after-tax income of residents that continue to claim the MID. Taxpayers for which the doubling of the standard deduction is only marginally beneficial are also hurt by the increase in tax rates and experience an income decrease. This negative income shock decreases the consumption of tradable and housing goods, negatively affecting the economy of the country and leading to a generalized wage decrease. However, because the cost of living decreases more than the decrease in the after tax income, renters and owner-occupiers experience a real income increase, with renters experiencing the biggest increase.

In the case of immobile renters and owner-occupiers, our analysis seems to suggest that doubling the standard deduction is beneficial, at least in terms of real income. When people can adapt location and tenure choices with respect to the baseline scenario, however, we find that the welfare of the country decreases by 
Figure 4: Impact of doubling the standard deduction: MSAs vs. countryside

(a) Renters

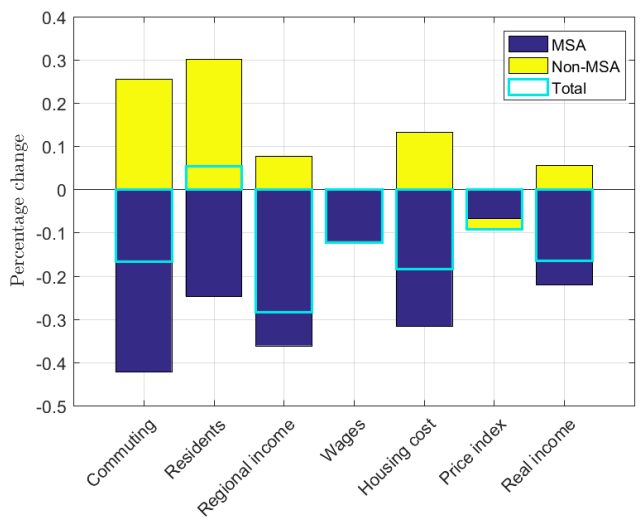

(b) Owners

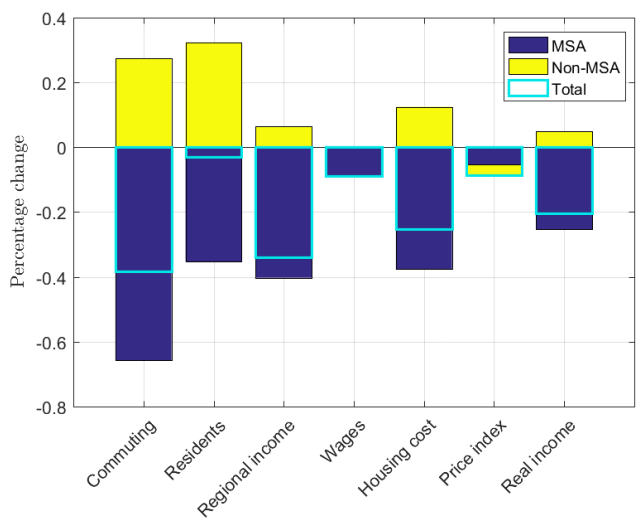

Note: We compute counterfactual changes by setting $s=12^{\prime} 717$ USD. Counterfactual tax rates adjust to keep federal public expenditure fixed. The header 'owners' denotes owner-occupiers. Workers can change place of residence, place of work, and tenure mode. MSAs are defined according to Saiz (2010). County-level counterfactual changes are aggregated using weighted averages based on the distribution of outcomes in the baseline scenario. Changes in commuting are weighted by the number of commuters. Changes in residents, (real) income, rents, and prices are weighted by the number of residents. Changes in wages are weighted by the number of workers.

0.05\%. We explain these results as follows. In the mobility scenario, because being an owner-occupier becomes relatively less attractive in most locations, many individuals switch tenure and/or relocate to areas displaying more elastic housing markets. ${ }^{32}$ This migration response to less productive areas further reinforces the regional income decrease, which lower the demand of tradable and housing goods even further with respect to the immobility case. The decrease in the price of tradable and housing goods is not strong enough to compensate the income decrease, which leads to a real income decrease, with renters experiencing a slightly less negative decrease. In turn, because the decrease in commuting flows does not compensate outweigh the decrease in real income, welfare decreases. Some of remaining owneroccupiers take advantage of lower housing costs to move closer to their work place, which results in a decrease of in-commuting.

Because, Table 4 only shows aggregate results for the whole of the country, in the next section we provide further evidence on the spatial displacement of the housing demand from MSAs to non-MSAs caused by the doubling of the standard deduction.

${ }^{32}$ The countrywide ownership rate is slightly reduced by 0.02 percentage points. 


\subsection{Changes in the spatial distribution}

Figure 4 shows the impact for renters (panel a) and owner-occupiers (panel b) living within/outside MSAs of doubling the standard deduction. As it can be seen, non-MSAs counties are strongly affected by the policy, with a clear shift of residents to less productive areas. In fact, countryside counties - which usually display more elastic housing markets - become relatively more attractive than counties located within MSAs for two reasons. First, the real value of the standard deduction is considerably higher in the countryside. Second, in these places the standard deduction capitalizes less into housing costs than in counties with a lower housing supply elasticity. As is shown in Figure 4, the shift to the countryside decreases housing costs in MSAs counties, while housing costs in the countryside increase. The shift to places with lower agglomeration economies reinforces the decrease in regional income of owner-occupiers and renters observed in Table 4. Because people have to move outside MSAs to benefit from the doubling of the standard deduction, we observe that incoming commuting flows of MSA counties strongly decrease, whereas those of countryside counties increase.

\section{Conclusions}

Over the last decades, the staggering tax expenditure generated by the mortgage interest deduction has fueled a lively debate among politicians and academicians regarding its allocative efficiency. Evidence on the economic impacts of the unequal geographic distribution of housing subsidies is currently missing. To analyze the economic effects of this unequal distribution, we develop a spatial general equilibrium model in which individuals respond endogenously to tax incentives by choosing where to live, where to work, and tenure mode. We calibrate our model with data for US counties, estimating, in particular, local housing supply elasticities. The

general applicability of the framework allows investigating a variety of simulations related to income-tax subsidies.

Simulation results suggest that repealing MID subsidies while keeping public expenditure constant leads to a moderate decrease in homeownership rates while 
slightly increasing the country welfare. The welfare gain is mostly due to a spatial displacement of the housing demand from congested housing markets in urban areas to more elastic housing markets in the countryside, and to a reduction in commuting flows between these areas. In contrast to previous research, we quantify the importance of spatial spillovers for the displacement response of residents due to a change in the subsidies, finding that they explain about one third of the response. In a separate simulation exercise, we show that a repeal of the MID is to be preferred to a lessening of its attractiveness via an increase of standard deductions as recently implemented under President Trump's administration.

Our results hold important lessons for the evaluation of housing and tax policies. Providing housing subsidies or income tax incentives significantly alters the geographic distribution of residents and workers across space, which in turn affects the aggregate efficiency of the policy. Non-local effects, arising via labor and goods markets, also influence the efficiency of the policy, especially in areas having strong spatial linkages with other ones. This prompts for a serious costs-benefits analysis of policies that target well-connected regions, such as major urban areas.

\section{References}

Albouy, D. (2009). The unequal geographic burden of federal taxation. Journal of Political Economy, 117(4):635-667.

Allen, T. and Arkolakis, C. (2014). Trade and the topography of the spatial economy. The Quarterly Journal of Economics, 129(3):1085-1140.

Allen, T., Arkolakis, C., and Li, X. (2016). On the existence and uniqueness of trade equilibria. mimeo.

Altonji, J. and Card, D. (1991). The effects of immigration on the labor market outcomes of less-skilled natives. In Abowd, J. and Freeman, R. B., editors, Immigration, Trade and Labor, pages 201-234. University of Chicago Press.

Armington, P. S. (1969). A theory of demand for products distinguished by place of production. IMF Staff Papers, 16:170-192. 
Bartik, T. J. (1991). Who benefits from state and local economic development policies? W.E. Upjohn Institute for Employment Research.

Baum-Snow, N. and Ferreira, F. (2015). Causal inference in urban and regional economics. Handbook of Regional and Urban Economics, 5:3-68.

Binner, A. and Day, B. (2015). Exploring mortgage interest deduction reforms: An equilibrium sorting model with endogenous tenure choice. Journal of Public Economics, 122:40-54.

Blouri, Y. and Ehrlich, M. v. (2019). On the optimal design of place-based policies: A structural evaluation of eu regional transfers. mimeo.

Bryan, G. and Morten, M. (2018). The aggregate productivity effects of internal migration: Evidence from Indonesia. Journal of Political Economy (Forthcoming).

Chapelle, G. and Eyméoud, J.-B. (2018). The housing supply elasticity and the cost of agglomeration. mimeo.

Davis, M. A. and Ortalo-Magne, F. (2011). Household expenditures, wages, rents. Review of Economic Dynamics, 14(2):248-261.

Dekle, R., Eaton, J., and Kortum, S. (2007). Unbalanced trade. American Economic Review, 97(2):351-355.

Diamond, R. (2016). The determinants and welfare implications of us workers' diverging location choices by skill: 1980-2000. American Economic Review, 106(3):479-524.

Diamond, R. (2017). Housing supply elasticity and rent extraction by state and local governments. American Economic Journal: Economic Policy, 9(1):74-111.

Eeckhout, J. and Guner, N. (2015). Optimal spatial taxation: Are big cities too small? mimeo.

Fajgelbaum, P. D., Morales, E., Suarez Serrato, J. C., and Zidar, O. (2019). State taxes and spatial misallocation. Review of Economic Studies (Forthcoming). 
Favilukis, J. and Van Nieuwerburgh, S. (2018). Out-of-town home buyers and city welfare. mimeo.

Glaeser, E. L. (2008). Cities, agglomeration, and spatial equilibrium. Oxford University Press., Oxford.

Glaeser, E. L., Kolko, J., and Saiz, A. (2001). Consumer city. Journal of Economic Geography, 1(1):27-50.

Gruber, J., Jensen, A., and Kleven, H. (2017). Do people respond to the mortage interest deduction? Quasi-experimental evidence from Denmark. NBER Working Paper No. 23600.

Gyourko, J. and Sinai, T. (2003). The spatial distribution of housing-related ordinary income tax benefits. Real Estate Economics, 31(4):527-575.

Heathcote, J., Storesletten, K., and Violante, G. L. (2017). Optimal tax progressivity: An analytical framework. The Quarterly Journal of Economics, 132(4):16931754 .

Hilber, C. and Robert-Nicoud, F. (2013). On the origins of land use regulations: Theory and evidence from US metro areas. Journal of Urban Economics, 75(C):29-43.

Hilber, C. A. L. and Turner, T. M. (2014). The mortgage interest deduction and its impact on homeownership decisions. Review of Economics and Statistics, 96(4):618-637.

Hsieh, C.-T. and Moretti, E. (2019). Housing constraints and spatial misallocation. American Economic Journal: Macroeconmics, 11(2):1-39.

Manson, S., Schroeder, J., Van Riper, D., and Ruggles, S. (2017). IPUMS national historical geographic information system: Version 12.0, database.

Monte, F., Redding, S. J., and Rossi-Hansberg, E. (2018). Commuting, migration and local employment elasticities. American Economic Review (Forthcoming).

Rappaport, J. (2007). Moving to nice weather. Regional Science and Urban Economics, 37(3):375-398. 
Redding, S. J. (2016). Goods trade, factor mobility and welfare. Journal of International Economics, 101:148-167.

Saiz, A. (2007). Immigration and housing rents in american cities. Journal of Urban Economics, 61(2):345 -371.

Saiz, A. (2010). The geographic determinants of housing supply. The Quarterly Journal of Economics, 125(3):1253-1296.

Simonovska, I. and Waugh, M. (2014). The elasticity of trade: Estimates and evidence. Journal of International Economics, 92(1):34-50.

Sinai, T. and Gyourko, J. (2004). The (un)changing geographical distribution of housing tax benefits: 1980 to 2000. Tax Policy and the Economy, 18:175-208.

Sommer, K. and Sullivan, P. (2018). Implications of US tax policy for house prices, rents, and homeownership. American Economic Review, 108(2):241-74.

Sommer, K., Sullivan, P., and Verbrugge, R. (2013). The equilibrium effect of fundamentals on house prices and rents. Journal of Monetary Economics, 60(7):854870 . 


\section{A Data appendix}

This section contains further information about data calibration, as well as additional descriptive statistics of the outcome variables of the model.

\section{A.1 Model calibration}

Table A.1: Calibration of the parameters

\begin{tabular}{lccl}
\hline Description & Notation & Value & Reference / Source \\
\hline Share of consumption expenditure & $\alpha$ & 0.7 & Davis and Ortalo-Magne (2011) \\
Share of public expenditure & $\beta$ & 0.22 & Fajgelbaum et al. (2019) \\
Agglomeration force & $\nu$ & 0.1 & Allen and Arkolakis (2014) \\
Elasticity of substitution & $\sigma$ & 5 & Simonovska and Waugh (2014) \\
Heterogeneity of preferences & $\epsilon$ & 3.3 & Monte et al. (2018) \\
Loan to house value ratio & $\xi$ & 0.51 & BGFRS \\
Mortgage interest rate & $\chi$ & 0.04 & ACS \\
Trade cost elasticity & $\psi$ & -1.29 & Monte et al. (2018) \\
Life span of housing structures & $t$ & 40 years ACS \\
Standard deduction & $s$ & $6358 \$$ & IRS \\
Housing supply elasticity & $\eta_{n}$ & - & Own estimation \\
\hline
\end{tabular}

Note: ACS: American Community Survey, BGFRS: Board of Governors of the Federal Reserve System, IRS: Internal Revenue Service. a) Simonovska and Waugh (2014) estimate $1-\sigma$ equal to a value of -4 , which implies $\sigma=5$.

\section{A.2 Summary statistics}

We present summary statistics of our exogenous and recovered variables in Table A.2. Figure A.1 shows the spatial distribution of selected observed and recovered variables of the model. 
Table A.2: Summary statistics

\begin{tabular}{lccccc}
\hline Variable & Mean & Std. Dev. & Min. & Max. & Obs. \\
\hline Production amenities $\left(\bar{a}_{n}\right)$ & 1.56 & 0.68 & 0.55 & 10.64 & 3056 \\
Commuters $\left(\bar{L} \sum_{n \neq i} \lambda_{n i}\right)$ & 15.87 & 61.27 & 0.01 & 2143.83 & 3056 \\
Renters $\left(\bar{L}^{R} \sum_{n \neq i} \lambda_{n i}^{R}\right)$ & 5.2 & 26.36 & 0 & 1156.34 & 3056 \\
Owners $\left(\bar{L}^{O} \sum_{n \neq i} \lambda_{n i}^{O}\right)$ & 10.67 & 36.56 & 0.01 & 987.49 & 3056 \\
Own trade shares, in \% $\left(\pi_{n n}\right)$ & 41.91 & 21.99 & 1.58 & 99.57 & 3056 \\
Housing supply elasticity $\left(\eta_{n}\right)$ & 1.69 & 0.44 & 0.39 & 2.25 & 3056 \\
Wages per-capita $\left(w_{n}\right)$ & 37.23 & 8.08 & 20.14 & 104.37 & 3056 \\
Income per-capita $\left(\bar{y}_{n}\right)$ & 54.85 & 7.4 & 40.38 & 112.07 & 3056 \\
Owners $\left(\bar{y}_{n}^{O}\right)$ & 56.94 & 7.97 & 42 & 119.85 & 3056 \\
Renters $\left(\bar{y}_{n}^{R}\right)$ & 49.46 & 6.53 & 37.15 & 100.66 & 3056 \\
Workers $\left(L_{n}\right)$ & 58.57 & 206.16 & 0.14 & 5939 & 3056 \\
Owners $\left(L_{n}^{O}\right)$ & 37.89 & 117.28 & 0.1 & 2876.75 & 3056 \\
Renters $\left(L_{n}^{R}\right)$ & 20.68 & 92.27 & 0.04 & 3062.25 & 3056 \\
Residents $\left(R_{n}\right)$ & 58.57 & 189.32 & 0.08 & 5734.31 & 3056 \\
Owners $\left(R_{n}^{O}\right)$ & 37.89 & 106.3 & 0.04 & 2689.48 & 3056 \\
Renters $\left(R_{n}^{R}\right)$ & 20.68 & 87.21 & 0.04 & 3044.83 & 3056 \\
Periodic cost of renting $\left(r_{n}^{R}\right)$ & 8.1 & 2.16 & 2.95 & 20.8 & 3056 \\
Periodic cost of ownership $\left(r_{n}^{O}\right)$ & 6.26 & 3.66 & 1.7 & 45.17 & 3056 \\
Price index $\left(P_{n}\right)$ & 7.5 & 1.15 & 2.19 & 10.31 & 3056 \\
Tax rates, in $\%(\tau)$ & 11.36 & 0 & 11.36 & 11.36 & 3056 \\
Owner's tax deduction $\left(\zeta_{n}\right)$ & 6.48 & 0.55 & 6.36 & 14.36 & 3056 \\
Ownership rate $\left(R_{n}^{O} / R_{n}\right)$ & 0.72 & 0.08 & 0.19 & 0.94 & 3056 \\
Sh. of commuters $\left(\bar{L}_{n \neq i} \sum_{n i} \lambda_{n i} / L_{i}\right)$ & 0.26 & 0.11 & 0.02 & 0.91 & 3056 \\
Owners $\left(\bar{L}^{O} \sum_{n \neq i} \lambda_{n i}^{O} / L_{i}^{O}\right)$ & 0.25 & 0.12 & 0.02 & 0.93 & 3056 \\
Renters $\left(\bar{L}^{R} \sum_{n \neq i} \lambda_{n i}^{R} / L_{i}^{R}\right)$ & 0.28 & 0.13 & 0.02 & 0.91 & 3056 \\
\hline
\end{tabular}

Note: Commuters, residents and workers are measured in thousand inhabitants, per capita wages, per capita income and rents are reported in thousand Dollars, Public good provision in million Dollars, and tax rates and trade shares in percent. 
Figure A.1: Overview of variables at the county level

(a) Wages $\left(w_{n}\right)$

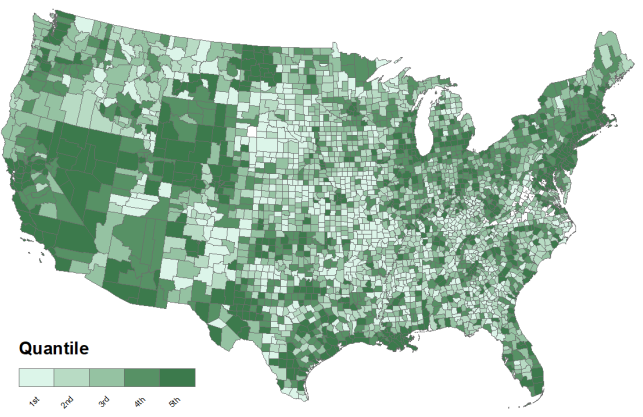

(c) Productivity $\left(a_{n}\right)$

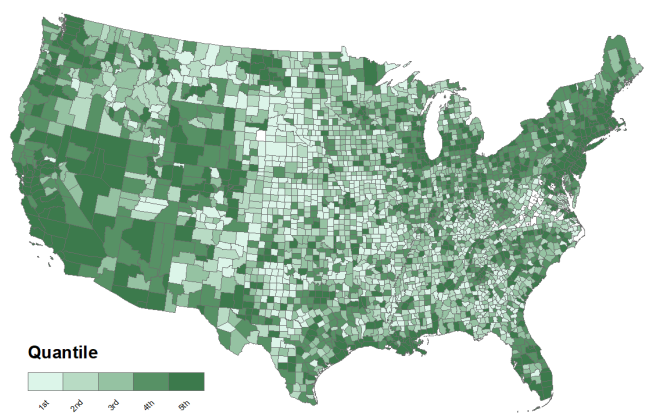

(b) Residents $\left(R_{n}\right)$

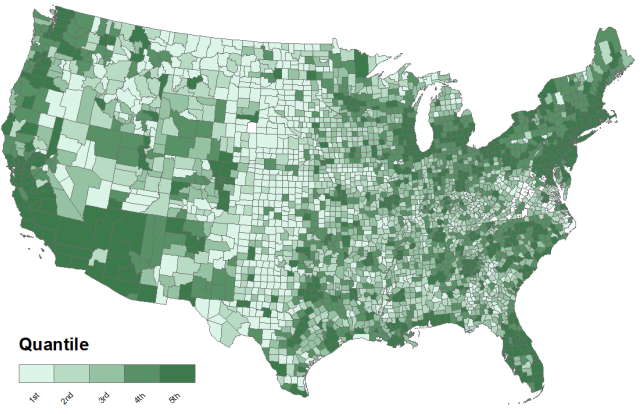

(d) Sh. of commuters - Owners $\left(\sum_{n \neq i} \lambda_{n i}^{O} / L_{i}^{O}\right)$

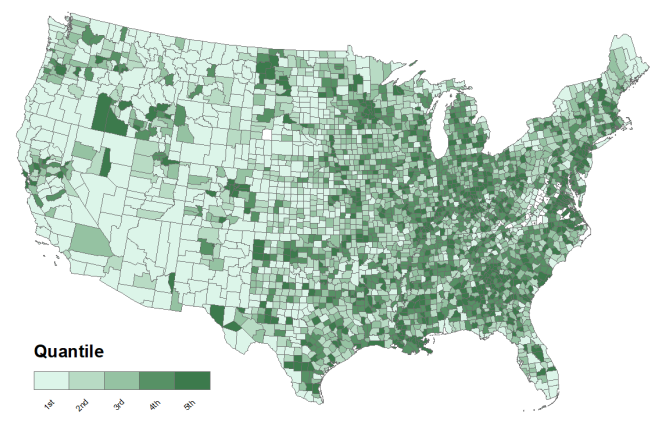

Note: We depict positive (negative) growth in green (red). A darker shading represents a stronger effect. 


\section{B Estimation of county-level housing supply elas- ticities}

In this section, we provide further information on the estimation of county-level housing supply elasticities and on the reliability of our estimates.

\section{B.1 From structure to empirics}

We show how the supply equations (13) can be used to derive the empirical specification (27). There are three main reasons to use (27) to estimate (inverse) housing supply elasticities. First, it is based on directly observable variables, namely changes in housing prices and housing stock growth. Second, it corresponds to Saiz (2010) specification of housing suppy elasticities, which allows us to investigate the validity of our estimates at the MSA level (see Section B.4). Third, it is easier to find instruments that capture relevant cross-sectional variation of the total housing stock.

Log-linearizing (13), first differencing, and rearranging the terms leads to

$$
\Delta \log \mathcal{P}_{n}^{\omega}=\alpha^{\omega}+\frac{1}{\eta_{n}} \Delta \log H_{n}^{\omega}+\bar{h}_{n}^{\omega}
$$

where the error term $\bar{h}_{n}^{\omega}$ corresponds to mean-centered changes of the supply shifter $\bar{H}_{n}^{\omega}$. According to the Cobb-Douglas utility function, the term $\Delta \log H_{n}^{\omega}$ represents tenure-specific changes of the total consumption of housing surface. We decompose this total housing consumption as $\Delta \log H_{n}^{\omega}=\Delta \log \mathrm{Q}_{n}+\Delta \log$ Share of $\omega_{n}+$ $\Delta \log$ Per capita $H_{n}^{\omega}$, where $Q_{n}$ denotes the total housing stock in a given county. We can thus rewrite (B.1) as

$$
\Delta \log \mathcal{P}_{n}^{\omega}=\alpha^{\omega}+\frac{1}{\eta_{n}} \Delta \log Q_{n}+\bar{h}_{n}^{\omega, *}
$$

The error term $\bar{h}_{n}^{\omega, *}$ now includes changes in the share of residents according to a given tenure mode and per capita housing consumption. Parametrizing the inverse 
housing supply elasticity $\frac{1}{\eta_{n}}$, we obtain

$$
\Delta \log \mathcal{P}_{n}^{\omega}=\alpha^{\omega}+\eta \Delta \log Q_{n}+\eta^{\text {built }} S_{n}^{\text {built }} \Delta \log Q_{n}+\bar{h}_{n}^{\omega, *}
$$

Because we assume the same housing supply elasticity for the rental and owneroccupied market, we drop the $\omega$ notation in the main text and use housing prices per square meter as dependent variable.

\section{B.2 Shift-share instrument based on ethnicity}

To calculate the shift-share instrument we follow Bartik (1991) and construct an exogenous housing demand shock by interacting the predetermined local ethnic composition of the population with the corresponding growth rates at the state level. The instrument should capture exogenous shifts of a given ethnicity at the county level while avoiding endogeneity issues associated with using local growth rates.

Denoting the shift-share ethnicity instrument for changes in the housing stock with $Z_{n}^{\Delta \log H}$, we use the following formula

$$
Z_{n}^{\Delta \log H}=\sum_{k} \gamma_{n, k} \eta_{k}
$$

where $\eta_{k}=\frac{P o p_{k,-n, 1990}-P o p_{k,-n, 1970}}{P o p_{k,-n, 1970}}$ represents the average ethnicity growth at the state level, excluding residents of county $n$, and $\gamma_{n, k}=\frac{P o p_{k n, 1970}}{P o p_{n, 1970}}$ denotes the local residential share of ethnicity $k$ at the beginning of the period. Ethnicity $k$ is defined according to the classification used in our data source assigning population to White, Black or African American, American Indian and Alaska Native, and Asian and Pacific Islander and other ethnicity residents.

\section{B.3 Controlling for local supply shifters}

One concern of our empirical specification is that unobserved supply dynamics contained in the error term of (27) correlate with the instruments, violating the exogeneity assumption necessary for the identification of the parameters. Therefore, 
Table B.1: County-level housing supply elasticity estimates including controls

\begin{tabular}{|c|c|c|c|c|}
\hline \multicolumn{5}{|c|}{ Dependent variable: Change in log housing prices $\left(\right.$ per $\left.m^{2}\right)$ between 1980 and $2000(\Delta \log \mathcal{P})$} \\
\hline \multirow[t]{2}{*}{ Instruments: } & Log-temperature & Fertility rate & $\begin{array}{l}\text { Shift-share } \\
\text { ethnicity }\end{array}$ & $\begin{array}{l}\text { All three } \\
\text { instruments }\end{array}$ \\
\hline & $(1)$ & $(2)$ & $(3)$ & (4) \\
\hline$\Delta \log Q$ & $\begin{array}{l}0.550^{* *} \\
(0.246)\end{array}$ & $\begin{array}{l}0.267 \\
(0.187)\end{array}$ & $\begin{array}{r}0.248^{*} \\
(0.151)\end{array}$ & $\begin{array}{l}0.299^{* *} \\
(0.151)\end{array}$ \\
\hline$S_{n}^{\text {built }} \Delta \log Q$ & $\begin{array}{l}2.196^{* * *} \\
(0.737)\end{array}$ & $\begin{array}{l}2.654^{* * *} \\
(0.666)\end{array}$ & $\begin{array}{l}2.470^{* * *} \\
(0.746)\end{array}$ & $\begin{array}{l}2.629^{* * *} \\
(0.759)\end{array}$ \\
\hline Controls & Yes & Yes & Yes & Yes \\
\hline Observations & 2.599 & 2.599 & 2.599 & 2.599 \\
\hline Underidentification $^{\mathrm{a}}$ & 0.002 & 0.000 & 0.002 & 0.002 \\
\hline Weak identification ${ }^{\mathrm{b}}$ & 7.986 & 12.342 & 7.709 & 21.342 \\
\hline Overidentification ${ }^{\mathrm{c}}$ & . & . & . & 0.685 \\
\hline
\end{tabular}

in this section we analyze the stability of the estimated coefficients to the inclusion of control variables in (27) that might proxy changes in the construction cost of housing and potentially correlate with demand changes. In particular, we control for changes of per capita payroll in the construction sector and for changes in the quality of the housing stock over the considered period. The housing characteristics we investigate are the median number of rooms, median building year, and share of detached single-family houses in the county. Data on per capita payroll from 1980 to 1997 stems from County Business Patterns (CBP), while housing characteristic in 1980 and 2000 is published by the US census. Both data sets are provided by IPUMS. In addition to housing characteristics, we control for relative changes in homeownership rates that are included in the dynamics of the error term according to Section B.1.

Table B.1 shows the results. Despite losing about $16 \%$ of the sample due to data unavailability at the county level, controlling for supply shifters does not strongly affect our main elasticity estimates. The coefficient of the main effect does become less significant for the different instruments, but it remains approximately within one and a half standard deviation of our main estimates. On the contrary, the coefficient of the interaction effect responsible for the heterogeneity of housing supply elasticities becomes even more significant while displaying the same magnitude. This 
seems to suggest that these observed dynamics of the construction sector do not considerably affect the value of our housing supply elasticities estimates.

\section{B.4 Comparison with Saiz (2010) MSAs elasticities}

In this section, we compare our housing supply elasticity estimates with those computed by Saiz (2010). To this end, we assign each county to a Metropolitan Statistical Area (MSA) and aggregate county-level elasticity using population weighted averages. As Figure B.1a illustrates, our estimates show a strong positive correlation of about 0.6 with those of Saiz (2010). However, as evident from this figure, we tend to recover higher housing supply elasticities as Saiz (2010). The reason for this higher number is that Saiz (2010) potentially underestimates housing supply elasticities, as housing transactions occurring within MSAs likely occur in dense and more inelastic places. 
Figure B.1: Comparison of housing supply elasticity with Saiz (2010)

(a) Comparison with Saiz (2010)

(b) Saiz (2010)
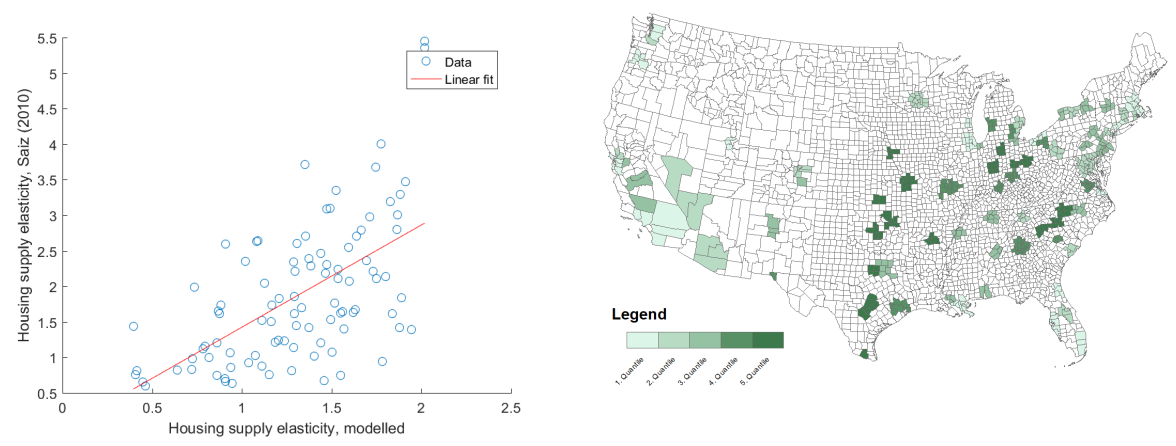

(c) Own-computation $\left(\eta_{n}\right)$

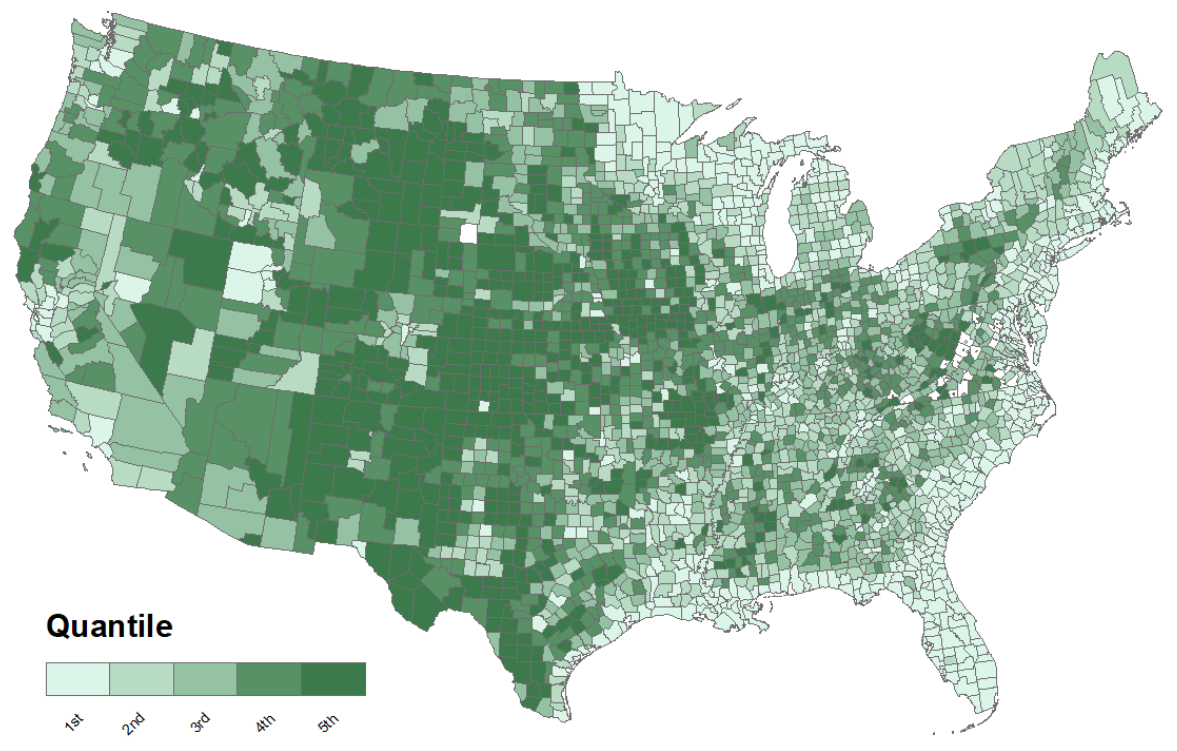

Note: In panel a) and b) we compare our housing supply elasticity with estimates described in Saiz (2010), which are based on US metropolitan statistical areas (MSA) and in b) estimates of Saiz (2010), respectively. A darker shading in the map indicates a higher quantile, i.e. more elastic places. In panel c) we show recovered housing supply elasticities of our model reported by quantiles. We compute the median value for counties belonging to the same MSA and get a correlation coefficient between Saiz (2010) and our measures of 0.6 . 


\section{Counterfactual analysis}

This section describes the system of equations that we use to simulate counterfactual policy experiments. Additionally, we provide complementary information on the simulation results presented in Section 4 and 5 of the main text.

\section{C.1 System of equations}

Let $\hat{x}=\frac{x^{\prime}}{x}$ denote a counterfactual change, where $x$ is an endogenous outcome variable of the baseline model and $x^{\prime}$ is its unobserved counterfactual value after a shock to the tax subsidies through $\theta$ or $s$. We solve the following system of equations with respect to counterfactual changes $\hat{x}$, where observed outcomes $x$ of the baseline specification play the role of parameters.

The counterfactual equation for wages directly follows from equilibrium wages (19):

$$
\hat{w}_{i} w_{i} \hat{L}_{i} L_{i}=\alpha \sum_{n \in N} \hat{\pi}_{n i} \pi_{n i} \hat{R}_{n} R_{n} \hat{\bar{y}}_{n} \bar{y}_{n}
$$

Counterfactual changes in the tenure-specific number of residents and workers are given by counterfactual changes in commuting flows, which can be derived from (25) and (26), respectively. This leads to

$$
\begin{aligned}
& \hat{R}_{n}^{\omega} R_{n}^{\omega}=\bar{L} \sum_{k \in N} \hat{\lambda}_{n k}^{\omega} \lambda_{n k}^{\omega}, \\
& \hat{L}_{n}^{\omega} L_{n}^{\omega}=\bar{L} \sum_{k \in N} \hat{\lambda}_{k n}^{\omega} \lambda_{k n}^{\omega} .
\end{aligned}
$$

As a consequence, the total number of residents and workers is

$$
\begin{gathered}
\hat{R}_{n} R_{n}=\hat{R}_{n}^{\mathcal{R}} R_{n}^{\mathcal{R}}+\hat{R}_{n}^{\mathcal{O}} R_{n}^{\mathcal{O}} \\
\hat{L}_{n} L_{n}=\hat{L}_{n}^{\mathcal{R}} L_{n}^{\mathcal{R}}+\hat{L}_{n}^{\mathcal{O}} L_{n}^{\mathcal{O}}
\end{gathered}
$$

We now turn to counterfactual changes to the per capita labor income of owneroccupiers. Because they have Cobb-Douglas preferences, households spend a constant fraction $(1-\alpha)$ of their income for housing consumption. It follows that 
$\frac{H_{n i}^{\mathcal{O}} r_{n}^{\mathcal{O}}}{\bar{L} \lambda_{n i}^{\mathcal{O}}}=(1-\alpha) y_{n i}^{\mathcal{O}}$. Using the definition of mortgage interest in (12) and expressing prices into a periodic cost as in $(2.4)$, we obtain that $m_{n i}=(1-\alpha) \phi y_{n i}^{\mathcal{O}}$, where $\phi=\xi \chi \frac{(1+\chi)\left(1-(1+\chi)^{-t}\right)}{\chi}$ defines the size of mortgage interests. Substituting these terms into (3) and rearranging yields the following elegant expression

$$
y_{n i}^{\mathcal{O}}=\frac{w_{i}-\tau\left(w_{i}-\zeta_{n i}\right)}{\alpha+\phi(1-\alpha)} .
$$

Using this equation, we can write the counterfactual equation of the per-capital labor income of owner-occupiers as

$$
\hat{y}_{n i}^{\mathcal{O}} y_{n i}^{\mathcal{O}}=\frac{\hat{w}_{i} w_{i}-\hat{\tau} \tau\left(\hat{w}_{i} w_{i}-\hat{\zeta}_{n i} \zeta_{n i}\right)}{\alpha+\phi(1-\alpha)}
$$

where counterfactual changes in tax subsidies are given by

$$
\hat{\zeta}_{n i} \zeta_{n i}=\max \left(s, \theta \hat{m}_{n i} m_{n i}\right)
$$

Note that because they represent exogenous parameters, we do not employ the hat notation for $s$ and $\theta$. However, depending on the simulation exercise, the reader must interpret $s$ or $\theta$ in (C.7) as the new value of the parameter that generates the initial shock to the system of equations.

Renters per capita labor income directly follows from (5)

$$
\hat{y}_{n i}^{\mathcal{R}} y_{n i}^{\mathcal{R}}=\hat{w}_{i} w_{i}-\hat{\tau} \tau\left(\hat{w}_{i} w_{i}-s\right)
$$

Using (8), we can write counterfactual changes in the tenure-specific total income, which includes both labor income and a redistributive term from the global portfolio, as

$$
\hat{\bar{y}}_{n}^{\omega} \bar{y}_{n}^{\omega}=\bar{L} \frac{\sum_{k \in N} \lambda_{n k}^{\omega} \hat{\lambda}_{n k}^{\omega}\left(\hat{y}_{n k}^{\omega} y_{n k}^{\omega}+\Pi \hat{\Pi}\right)}{\hat{R}_{n}^{\omega} R_{n}^{\omega}},
$$

where counterfactual changes in the portfolio are given by

$$
\Pi \hat{\Pi}=\hat{G} G+\sum_{k, f}\left(\hat{\lambda}_{k f}^{\mathcal{O}} \lambda_{k f}^{\mathcal{O}} m_{k f} \hat{m}_{k f}+(1-\alpha) y_{k f}^{\mathcal{R}} \hat{y}_{k f}^{\mathcal{R}} \hat{\lambda}_{k f}^{\mathcal{R}} \lambda_{k f}^{\mathcal{R}}\right),
$$


Using (7), counterfactual changes of total income must satisfy

$$
\hat{\bar{y}}_{n} \bar{y}_{n}=\frac{1}{\hat{R}_{n} R_{n}}\left(\hat{\bar{y}}_{n}^{\mathcal{R}} \bar{y}_{n}^{\mathcal{R}} \hat{R}_{n}^{\mathcal{R}} R_{n}^{\mathcal{R}}+\hat{\bar{y}}_{n}^{\mathcal{O}} \bar{y}_{n}^{\mathcal{O}} \hat{R}_{n}^{\mathcal{O}} R_{n}^{\mathcal{O}}\right)
$$

Using (15), we obtain a counterfactual productivity given by

$$
\hat{a}_{n}=\hat{L}_{n}^{\nu}
$$

Changes in the consumption price index are derived from (18) and must satisfy

$$
\hat{P}_{n}=\left(\frac{1}{\hat{\pi}_{n n}}\right)^{1 /(1-\sigma)} \frac{\hat{w}_{n}}{\hat{a}_{n}} .
$$

Counterfactual changes in the tenure-specific cost of housing follow from (14) and are equal to

$$
\hat{r}_{n}^{\omega}=\left(\hat{\bar{y}}_{n}^{\omega} \hat{R}_{n}^{\omega}\right)^{\frac{1}{1+\eta_{n}}}
$$

We compute counterfactual changes in mortgage interest by substituting (10) and (2.4) into (12), such that

$$
\hat{m}_{n i}=\hat{y}_{n i}^{\mathcal{O}}
$$

Counterfactual trade shares are obtained using (17), which leads to

$$
\hat{\pi}_{n i}=\frac{\left(\frac{\hat{w}_{i}}{\hat{a}_{i}}\right)^{1-\sigma}}{\sum_{k \in N}\left(\frac{\hat{w}_{k}}{\hat{a}_{k}}\right)^{1-\sigma} \pi_{n k}} .
$$

Finally, we express tenure-specific counterfactual changes in commuting flows by dividing the counterfactual population mobility condition by the equilibrium mobility condition (22):

$$
\hat{\lambda}_{n i}^{\omega}=\frac{(\hat{G})^{\beta \epsilon}\left(\frac{\hat{y}_{n i}^{\omega}}{\hat{P}_{n}^{\alpha} \hat{r}_{n}^{\omega 1-\alpha}}\right)^{(1-\beta) \epsilon}}{\sum_{l \in \omega} \sum_{f \in N} \sum_{k \in N}(\hat{G})^{\beta \epsilon}\left(\frac{\hat{y}_{k f}^{l}}{\hat{P}_{k}^{\alpha} \hat{r}_{k}^{l 1-\alpha}}\right)^{(1-\beta) \epsilon} \lambda_{k f}^{l}} .
$$

Note that (C.12) to (C.17) are expressed in terms of counterfactual changes (and not values) because the baseline level of the considered outcome is simplified. 
Figure C.1: MSAs vs. countryside: Renters and owner-occupiers

(a) Repealing the MID

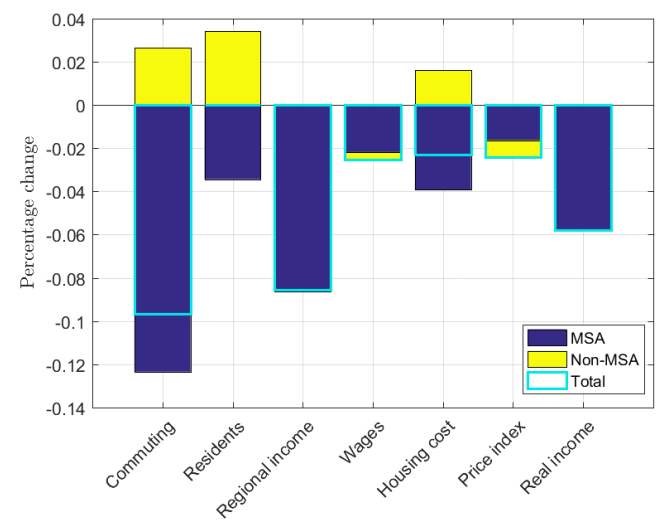

(b) Doubling the standard deduction

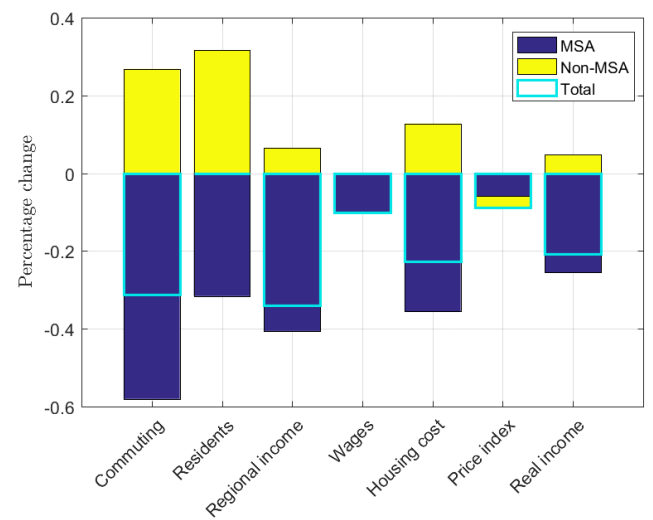

Note: Panel a) depicts counterfactual changes by setting $\theta=0$ and Panel b) depicts counterfactual changes by setting $s=12^{\prime} 717$ USD. Workers can change place of residence, work and tenure mode. MSAs are defined according to Saiz (2010). County-level counterfactual changes are aggregated using weighted averages based on the distribution of outcomes in the baseline scenario. Changes in commuting are weighted by the number of commuters. Changes in residents, (real) income, prices, and housing costs are weighted by the number of residents. Changes in wages are weighted by the number of workers.

We compute changes in the provision of the public good using (9)

$$
\begin{aligned}
\hat{G} G=\frac{1}{\bar{L}} \sum_{n \in N}( & \bar{L} \tau \hat{\tau} \sum_{k \in N} \hat{\lambda}_{n k}^{\mathcal{R}} \lambda_{n k}^{\mathcal{R}}\left(w_{k} \hat{w}_{k}-s\right) \\
& \left.+\bar{L} \tau \hat{\tau} \sum_{k \in N} \hat{\lambda}_{n k}^{\mathcal{O}} \lambda_{n k}^{\mathcal{O}}\left(w_{k} \hat{w}_{k}-\hat{\zeta}_{n k} \zeta_{n k}\right)\right) .
\end{aligned}
$$

Equations (C.1)-(C.18) hold for each location and allow us to solve the system for counterfactual changes in commuting $\hat{\lambda}_{n i}^{\omega}$, public good provision $\hat{G}$, and real income $\frac{\hat{y}_{n i}^{\omega}}{\hat{P}_{n}^{\alpha} \hat{r}_{n}^{\omega 1-\alpha}}$. These changes build up the counterfactual value of the welfare, which using (24) is given by

$$
\widehat{\bar{V}}=\left(\frac{1}{\widehat{\lambda}_{n i}^{\omega}}\right)^{\frac{1}{\epsilon}}(\hat{G})^{\beta}\left(\frac{\widehat{y}_{n i}^{\omega}}{\hat{P}_{n}^{\alpha} \widehat{r}_{n}^{1-\alpha}}\right)^{1-\beta},
$$

where counterfactual changes in utility are equalized across space and tenure such that no welfare arbitrage is possible across location and tenure mode. 


\section{C.2 Changes in the spatial distribution: further details}

To complement our counterfactual analysis of Section 4 and 5, we show how tax subsidy reforms affects the spatial distribution of people, wage, and income across space when adding renters and owner-occupiers together. Figure C.1 shows decomposition between MSAs and non-MSAs counties in the case of a repeal of the MID (panel a) and for a doubling of the standard deduction (panel b), respectively. Additionally, in Table C.1, we illustrate how these changes in the tax subsidies affect the spatial dispersion of income across locations. Finally, figure C.2 shows additional maps on the spatial distribution of main outcomes in the case of a repeal of the MID.

Table C.1: Impact of tax-subsidy reforms on spatial concentration

\begin{tabular}{|c|c|c|c|c|c|c|}
\hline & \multicolumn{3}{|c|}{ Repealing the MID } & \multicolumn{3}{|c|}{ Doubling the standard deduction } \\
\hline & Renters & Owners & Total & Renters & Owners & Total \\
\hline & $(1)$ & $(2)$ & $(3)$ & $(4)$ & $(5)$ & $(6)$ \\
\hline \multicolumn{7}{|l|}{ Counterfactual changes (in \%) } \\
\hline Workers $\left(\widehat{\operatorname{Gini}}\left(L_{n}\right)\right)$ & -0.01 & -0.06 & -0.03 & -0.26 & -0.39 & -0.34 \\
\hline Residents $\left(\widehat{\operatorname{Gini}}\left(R_{n}\right)\right)$ & -0.01 & -0.06 & -0.03 & -0.24 & -0.38 & -0.33 \\
\hline Income $\left(\widehat{\operatorname{Gini}}\left(y_{n i}\right)\right)$ & -0.05 & -0.59 & -0.46 & -3.04 & -3.55 & -3.46 \\
\hline Real income $\left(\widehat{\operatorname{Gini}}\left(y_{n i} / P_{n}^{\alpha} r_{n}^{1-\alpha}\right)\right)$ & -0.04 & -0.40 & -0.31 & -2.21 & -2.56 & -2.52 \\
\hline
\end{tabular}

Note: Columns 1 to 3 report counterfactual changes obtained by setting $\theta=0$, and columns 4 to 6 report counterfactual changes obtained by setting $s=12^{\prime} 717$ USD. Workers can change place of residence, work and tenure mode.

\section{C.3 MID repeal: Varying public good provision}

The MID repeal directly impacts the tax revenue of the federal government. In our benchmark model, the federal government adjusts tax rates to maintain public good provision constant. In this section, we validate our main results by assessing the welfare impact of the repeal when the federal government does adjust public good provision in response to the repeal while keeping income tax rates constant. Table C.2 shows the results. As it can be seen, in this setting the repeal leaves the response of location and tenure choices mostly unaffected and leads to a higher welfare increase. However, renters experience a negative (real) income change, as they do not benefit from lower income tax rates anymore. Figure C.3 shows that our 
Figure C.2: Repealing the Mortgage Interest Deduction: County-level counterfactual changes

(a) Wages $\left(\hat{w}_{n}\right)$

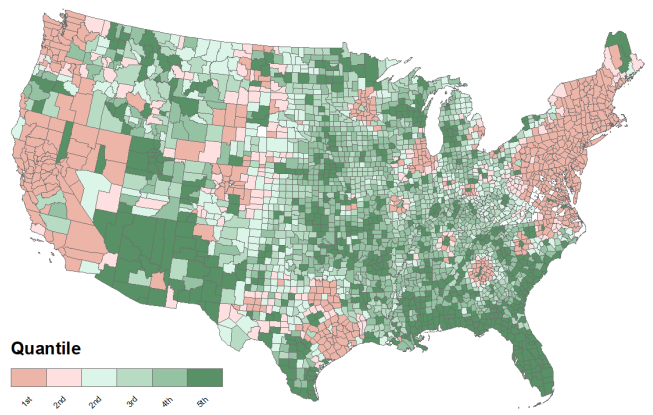

(c) Productivity $\left(\hat{a}_{n}\right)$

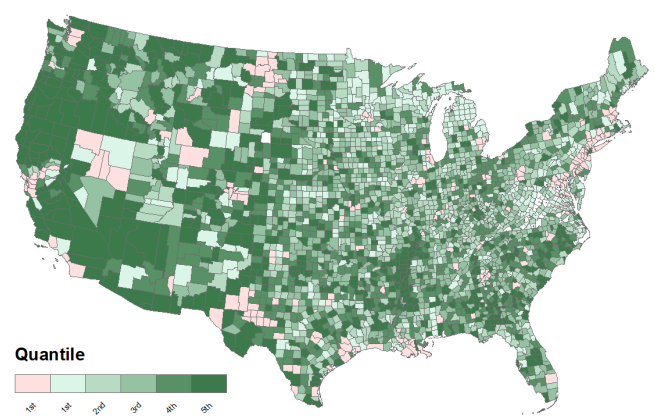

(e) In-commuters - Owners $\left(\widehat{\sum_{n \neq i} \lambda_{n i}^{O}}\right)$

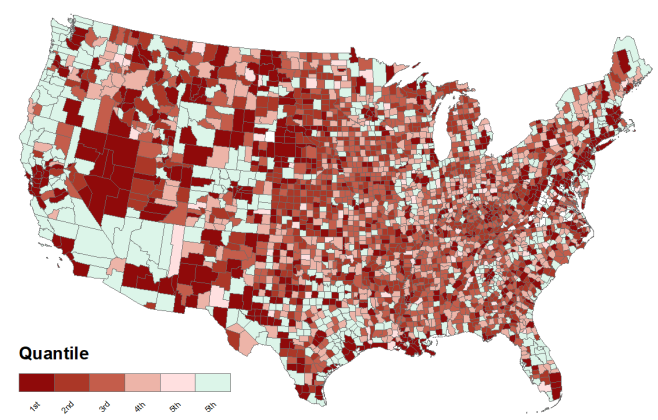

(b) Residents $\left(\hat{R}_{n}\right)$

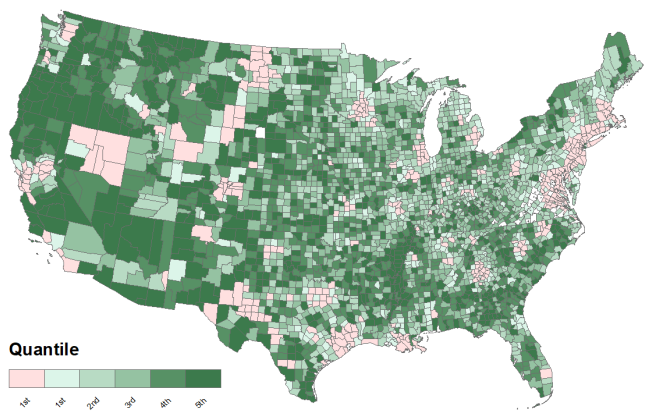

(d) In-commuters sh. - Own. $\left(\widehat{\sum_{n \neq i} \lambda_{n i}^{O}} / \hat{L}_{i}^{O}\right)$

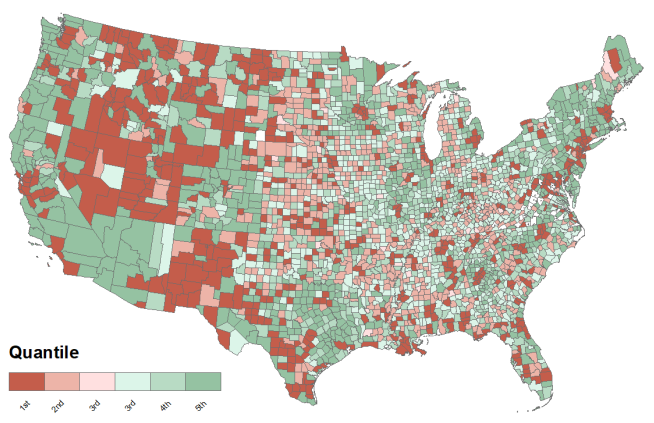

(f) Periodic housing cost - Renters $\left(\hat{r}_{n}^{R}\right)$

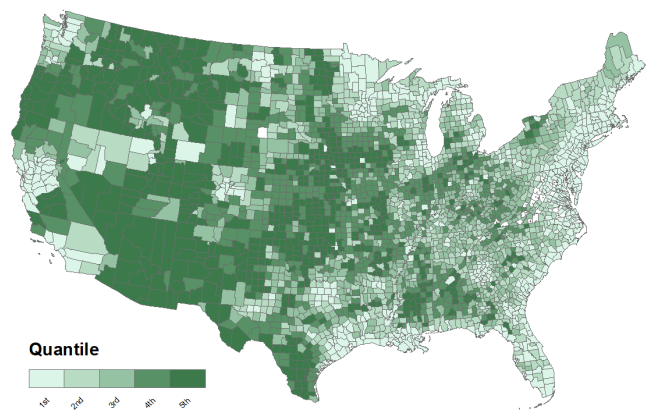

Note: We compute counterfactual changes by setting $\theta=0$. The header 'owners' denotes owner-occupiers. Workers can change place of residence, place of work, and tenure mode. We depict positive (negative) growth in green (red). A darker shading represents a stronger effect. 
Table C.2: Repealing the Mortgage Interest Deduction

\begin{tabular}{|c|c|c|c|c|c|c|}
\hline & \multicolumn{3}{|c|}{$\begin{array}{l}\text { Keeping location and } \\
\text { tenure choices fixed }\end{array}$} & \multicolumn{3}{|c|}{$\begin{array}{l}\text { Varying location and } \\
\text { tenure choices }\end{array}$} \\
\hline & Renters & Owners & Total & Renters & Owners & Total \\
\hline & (1) & $(2)$ & $(3)$ & $(4)$ & $(5)$ & $(6)$ \\
\hline \multicolumn{7}{|l|}{ Counterfactual changes (in \%) } \\
\hline Welfare $\left(\hat{V}_{n}\right)$ & - & - & - & 0.17 & 0.17 & 0.17 \\
\hline Commuting $\left(\sum_{n \neq i} \lambda_{n i}^{\prime} / \sum_{n \neq i} \lambda_{n i}\right)$ & - & - & - & 0.53 & -0.40 & -0.10 \\
\hline Residents $\left(\hat{R}_{n}\right)$ & - & - & - & 0.53 & -0.29 & - \\
\hline Regional income $\left(\hat{y}_{n i}\right)$ & -0.04 & -0.20 & -0.15 & -0.03 & -0.23 & -0.20 \\
\hline Wages $\left(\hat{w}_{i}\right)$ & -0.04 & -0.03 & -0.03 & -0.03 & -0.03 & -0.03 \\
\hline Housing costs $\left(\hat{r}_{n}\right)$ & 0.02 & -0.06 & -0.03 & 0.28 & -0.22 & -0.04 \\
\hline Price index $\left(\hat{P}_{n}\right)$ & -0.04 & -0.04 & -0.04 & -0.03 & -0.03 & -0.03 \\
\hline Real income $\left(\hat{y}_{n i} / \hat{P}_{n}^{\alpha} \hat{r}_{n}^{1-\alpha}\right)$ & -0.01 & -0.16 & -0.11 & -0.09 & -0.14 & -0.16 \\
\hline
\end{tabular}

results concerning the shift of economic activity from MSA to non-MSA counties are still valid. 
Figure C.3: Repealing the MID: MSAs vs. countryside

(a) Renters

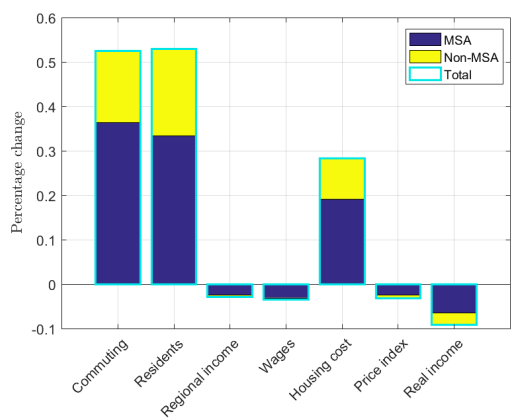

(b) Owners

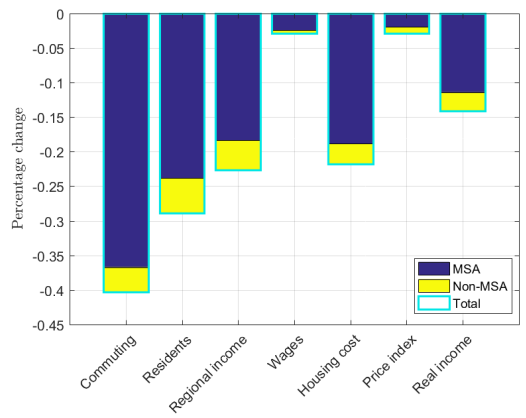

(c) Renters and owners

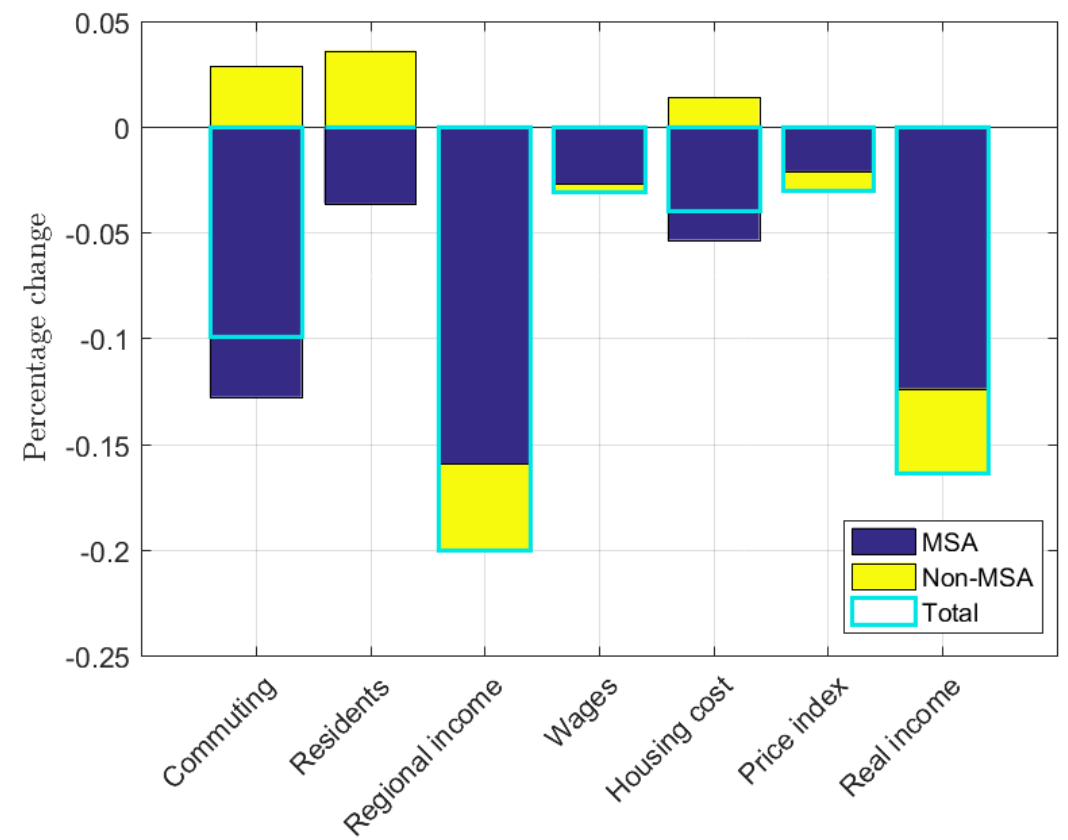

Note: The figure depicts counterfactual changes obtained by setting $\theta=0$. The header 'owners' denotes owner-occupiers. Workers can change place of residence, work and tenure mode. MSAs are defined according to Saiz (2010). County-level counterfactual changes are aggregated using weighted averages based on the distribution of outcomes in the baseline scenario. Changes in commuting are weighted by the number of commuters. Changes in residents, (real) income, prices, and housing costs are weighted by the number of residents. Changes in wages are weighted by the number of workers. 


\section{Model's extensions}

In this section, we formalize two model extensions and present counterfactual results in the case of a MID repeal.

\section{D.1 Property taxation}

Property taxes account for less than $1 \%$ of the US federal tax revenue. However, because deductible from the taxable income at the federal level, local property taxes might affect the welfare and sorting decisions of individuals according to MID subsidies. In this section, we thus investigate the robustness of our results when households can deduct local property taxes from their taxable income in addition to MID subsidies.

In what follows we outline which equations of our baseline model change. Let $\tau_{n}^{p}$ denote local (county-level) property tax rates. Because owner-occupiers pay property taxes on the local housing value $\frac{1}{\iota} \frac{H_{n i}^{\mathcal{O}} r_{n}^{\mathcal{O}}}{\bar{L} \lambda_{n i}^{\mathcal{O}}}$, their regional income is

$$
y_{n i}^{\mathcal{O}}=w_{i}-\tau\left(w_{i}-\zeta_{n i}\right)+\left(1-\frac{\tau_{n}^{p}}{\iota}\right) \frac{H_{n i}^{\mathcal{O}} r_{n}^{\mathcal{O}}}{\bar{L} \lambda_{n i}^{\mathcal{O}}}-m_{n i}
$$

where $\zeta_{n i}$ is given by

$$
\zeta_{n i}=\max \left(s, \theta m_{n i}+\frac{\tau_{n}^{p}}{\iota} \frac{H_{n i}^{\mathcal{O}} r_{n}^{\mathcal{O}}}{\bar{L} \lambda_{n i}^{\mathcal{O}}}\right)
$$

When choosing whether to itemize, owner-occupiers thus weigh the mortgage interests and property taxes against the standard deduction. We can rewrite the disposable income of owner-occupiers as

$$
y_{n i}^{\mathcal{O}}=\frac{w_{i}-\tau\left(w_{i}-\zeta_{n i}\right)}{\alpha+\left(\frac{\tau_{n}^{p}}{\iota}+\phi\right)(1-\alpha)} .
$$

From (D.3) it is apparent that property taxation decreases the income of owneroccupiers with respect to our benchmark model.

To keep our model parsimonious, we assume that the tax revenue generated by 
Table D.1: Repealing the Mortgage Interest Deduction

\begin{tabular}{|c|c|c|c|c|c|c|}
\hline & \multicolumn{3}{|c|}{$\begin{array}{l}\text { Keeping location and } \\
\text { tenure choices fixed }\end{array}$} & \multicolumn{3}{|c|}{$\begin{array}{l}\text { Varying location and } \\
\text { tenure choices }\end{array}$} \\
\hline & Renters & Owners & Total & Renters & Owners & Total \\
\hline & (1) & $(2)$ & $(3)$ & $(4)$ & $(5)$ & $(6)$ \\
\hline \multicolumn{7}{|l|}{ Counterfactual changes (in \%) } \\
\hline Welfare $\left(\hat{V}_{n}\right)$ & - & - & - & 0 & 0 & 0 \\
\hline Commuting $\left(\sum_{n \neq i} \lambda_{n i}^{\prime} / \sum_{n \neq i} \lambda_{n i}\right)$ & - & - & - & 0.76 & -0.57 & -0.13 \\
\hline Residents $\left(\hat{R}_{n}\right)$ & - & - & - & 0.76 & -0.42 & - \\
\hline Regional income $\left(\hat{y}_{n i}\right)$ & 0.13 & -0.10 & -0.03 & 0.12 & -0.16 & -0.10 \\
\hline Wages $\left(\hat{w}_{i}\right)$ & -0.04 & -0.03 & -0.03 & -0.04 & -0.03 & -0.03 \\
\hline Housing costs $\left(\hat{r}_{n}\right)$ & 0.04 & -0.06 & -0.02 & 0.43 & -0.28 & -0.03 \\
\hline Price index $\left(\hat{P}_{n}\right)$ & -0.04 & -0.04 & -0.04 & -0.03 & -0.03 & -0.03 \\
\hline Real income $\left(\hat{y}_{n i} / \hat{P}_{n}^{\alpha} \hat{r}_{n}^{1-\alpha}\right)$ & 0.15 & -0.06 & 0.01 & 0.01 & -0.06 & -0.07 \\
\hline
\end{tabular}

property taxation is collected by the federal government and equally redistributed to workers. The federal budget must be balanced, such that

$$
G=\frac{1}{\bar{L}} \sum_{n \in N}\left(\tau \bar{L} \sum_{k \in N} \lambda_{n k}^{\mathcal{R}}\left(w_{k}-s\right)+\tau \bar{L} \sum_{k \in N} \lambda_{n k}^{\mathcal{O}}\left(w_{k}-\zeta_{n k}\right)+\frac{\tau_{n}^{p}}{\iota} H_{n}^{\mathcal{O}} r_{n}^{\mathcal{O}}\right)
$$

This approach allows us focus on the effect of the increase in tax deductions caused by property taxation without diving into considerations regarding the amount of local public good provision provided by local governments. In fact, note that the denominator in (D.3) simplifies in our counterfactual simulations, such that $\zeta_{n i}$ is the main terms through which property taxation acts on workers' choices.

In our counterfactual simulations we set $\tau_{n}^{p}=0.01$ across all location, This rate, which is based on the ACS 2009-2013, corresponds to the median payment of real estate taxes for the median housing value. We adjust the standard deduction to 8857 USD to match the observed itemization rate of individuals itemizing the MID. Table D.1 and Figure D.1 reports simulation results for repealing the MID in the presence of property taxes. 
Figure D.1: Impact of eliminating MID: Decomposing welfare effects

(a) Renters

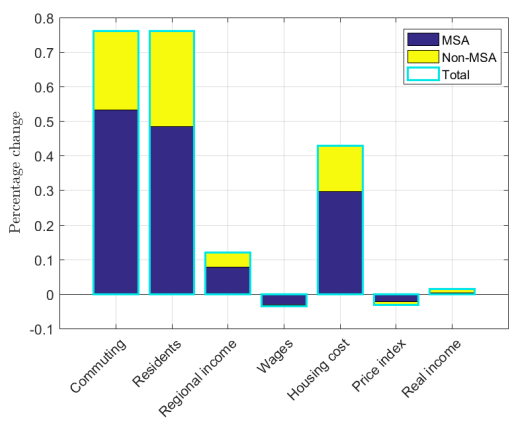

(b) Owners

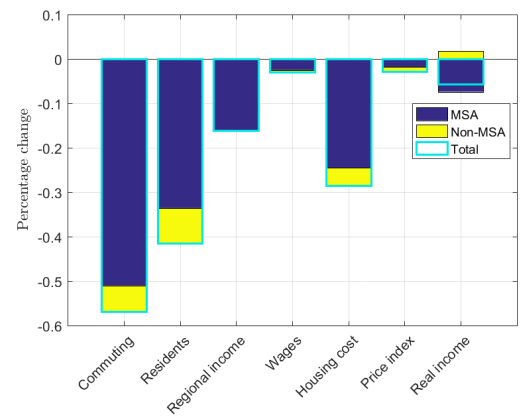

(c) Renters and owners

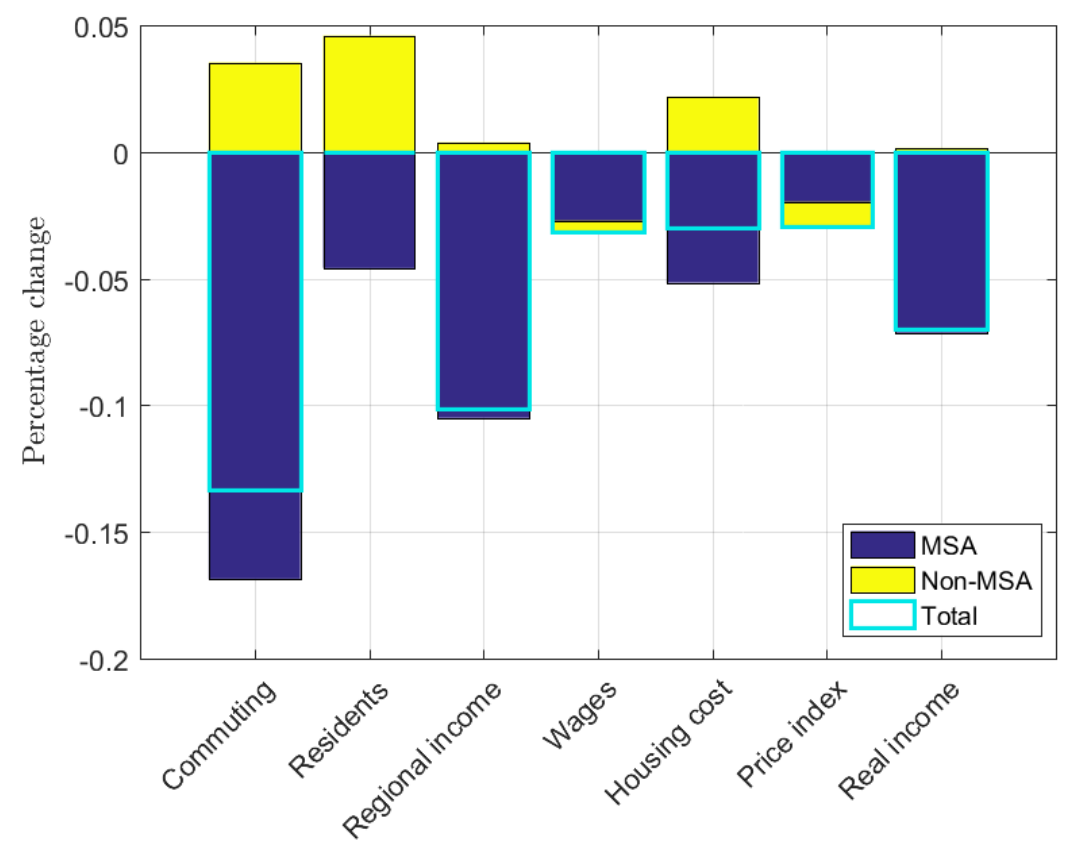

The figure depicts counterfactual changes obtained by setting $\theta=0$. The header 'owners' denotes owneroccupiers. Workers can change place of residence, work and tenure mode. MSAs are defined according to Saiz (2010). County-level counterfactual changes are aggregated using weighted averages based on the distribution of outcomes in the baseline scenario. Changes in commuting are weighted by the number of commuters. Changes in residents, (real) income, prices, and housing costs are weighted by the number of residents. Changes in wages are weighted by the number of workers.

\section{D.2 Progressive tax schedule}

In general, tax deductions become more valuable with rising income due to the progressivity of the tax system. Because tax progressivity makes the MID a regressive subsidy, it creates an additional systematic link between a location's productivity and the tax incentives for owner-occupiers to live in that location. We test the 
robustness of our main results with respect to this additional sorting effect.

In what follows we illustrate how a progressive income taxation affects the equations of our baseline model. In line with the literature, we model progressive tax rates by introducing a parameter $v>0$ governing the progressivity. ${ }^{33}$ The per-capita income of owner-occupiers is

$$
y_{n i}^{\mathcal{O}}=w_{i}-\tau_{n i}^{O}\left(w_{i}-\zeta_{n i}\right)+\frac{H_{n i}^{\mathcal{O}} r_{n}^{\mathcal{O}}}{\bar{L} \lambda_{n i}^{\mathcal{O}}}-m_{n i},
$$

where $\zeta_{n i}=\max \left(s, \theta m_{n i}\right)$ and the tax rate relevant for homeowners is given by $1-\tau_{n i}^{O}=(1-\tau)\left(w_{i}-\zeta_{n i}\right)^{-v}$. Renters' income is

$$
y_{n i}^{\mathcal{R}}=w_{i}-\tau_{i}^{R}\left(w_{i}-s\right),
$$

where the relevant tax rate is given by $1-\tau_{i}^{R}=(1-\tau)\left(w_{i}-s\right)^{-v}$. The MID thus creates a tax rate differential between owner-occupiers and renters because it shifts taxable labor income according to tenure mode. Tax payments of owner-occupiers and renters are given by

$$
T_{n i}^{\mathcal{O}}=w_{i}-(1-\tau)\left(w_{i}-\zeta_{n i}\right)^{1-v}
$$

and

$$
T_{i}^{\mathcal{R}}=w_{i}-(1-\tau)\left(w_{i}-s\right)^{1-v}
$$

respectively. Per capita tax revenue of the federal government must equal per capita public good provision, such that

$$
G=\frac{1}{\bar{L}} \sum_{n \in N}\left(\bar{L} \sum_{\omega} \sum_{k \in N} \lambda_{n k}^{\omega} T_{k}^{\omega}\right)
$$

A tax schedule is defined as progressive if marginal tax rates $\frac{\partial T^{\omega}}{\partial w}$ exceed the average tax rates $\frac{T^{\omega}}{w}$ for every level of wages $w_{n}$. This is true for renters and owner-occupiers if $v>0$ and MID subsidies do not exist $(\theta=0)$. However, if $v>0$ and MID subsidies are fully deductible $(\theta=1)$, the tax schedule is not

\footnotetext{
${ }^{33}$ see Eeckhout and Guner (2015), Heathcote et al. (2017) or Fajgelbaum et al. (2019).
} 
Table D.2: Repealing the Mortgage Interest Deduction

\begin{tabular}{|c|c|c|c|c|c|c|}
\hline & \multicolumn{3}{|c|}{$\begin{array}{l}\text { Keeping location and } \\
\text { tenure choices fixed }\end{array}$} & \multicolumn{3}{|c|}{$\begin{array}{l}\text { Varying location and } \\
\text { tenure choices }\end{array}$} \\
\hline & Renters & Owners & Total & Renters & Owners & Total \\
\hline & (1) & $(2)$ & $(3)$ & $(4)$ & $(5)$ & (6) \\
\hline \multicolumn{7}{|l|}{ Counterfactual changes (in \%) } \\
\hline Welfare $\left(\hat{V}_{n}\right)$ & - & - & - & 0.01 & 0.01 & 0.01 \\
\hline Commuting $\left(\sum_{n \neq i} \lambda_{n i}^{\prime} / \sum_{n \neq i} \lambda_{n i}\right)$ & - & - & - & 1.14 & -0.81 & -0.17 \\
\hline Residents $\left(\hat{R}_{n}\right)$ & - & - & - & 1.10 & -0.60 & - \\
\hline Regional income $\left(\hat{y}_{n i}\right)$ & 0.21 & -0.13 & -0.03 & 0.20 & -0.21 & -0.15 \\
\hline Wages $\left(\hat{w}_{i}\right)$ & -0.03 & -0.03 & -0.03 & -0.04 & -0.04 & -0.04 \\
\hline Housing costs $\left(\hat{r}_{n}\right)$ & 0.08 & -0.07 & -0.02 & 0.64 & -0.40 & -0.02 \\
\hline Price index $\left(\hat{P}_{n}\right)$ & -0.04 & -0.03 & -0.04 & -0.04 & -0.04 & -0.04 \\
\hline Real income $\left(\hat{y}_{n i} / \hat{P}_{n}^{\alpha} \hat{r}_{n}^{1-\alpha}\right)$ & 0.21 & -0.09 & 0.01 & 0.03 & -0.06 & -0.11 \\
\hline
\end{tabular}

necessarily progressive over the entire wage distribution of owner-occupiers. In fact, because owner-occupiers spend a constant share of their income for housing, the MID counteracts the progressive nature of the tax schedule. In this setting, at a specific cut-off point of the income distribution the tax schedule changes from regressive to progressive.

Our benchmark model features no tax progressivity $(v=0)$, thus imposing that marginal tax rates are equal to average tax rates. To introduce tax rate progressivity, we calibrate the progressivity parameter according to Eeckhout and Guner (2015), who estimate $v=0.12$ for the US income tax system. We adapt the standard deduction to 6341 USD to match the observed share of people itemizing MID subsidies according to IRS data. Additionally, we calibrate the tax shifter $\tau$ to match the government revenue of our benchmark chase, such that the results in the case of progressive tax rates are not affected by changes in public expenditure at the federal level. Table D.2 and Figure D.2 report the results of repealing the MID in the presence of tax progressivity. 
Figure D.2: Impact of eliminating MID: Decomposing welfare effects

(a) Renters

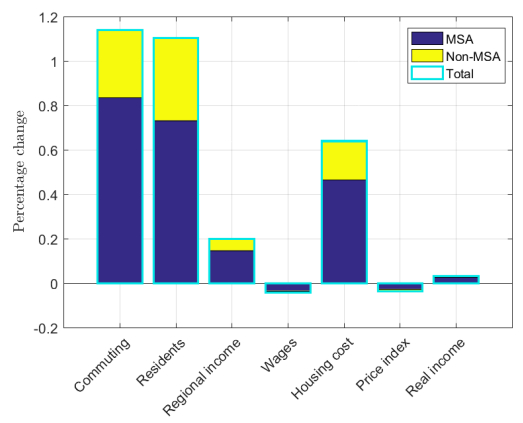

(b) Owners

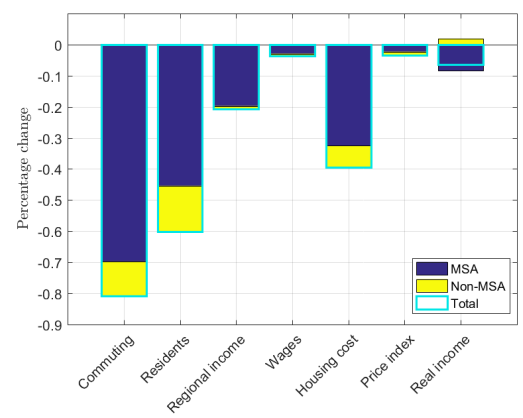

(c) Renters and owners

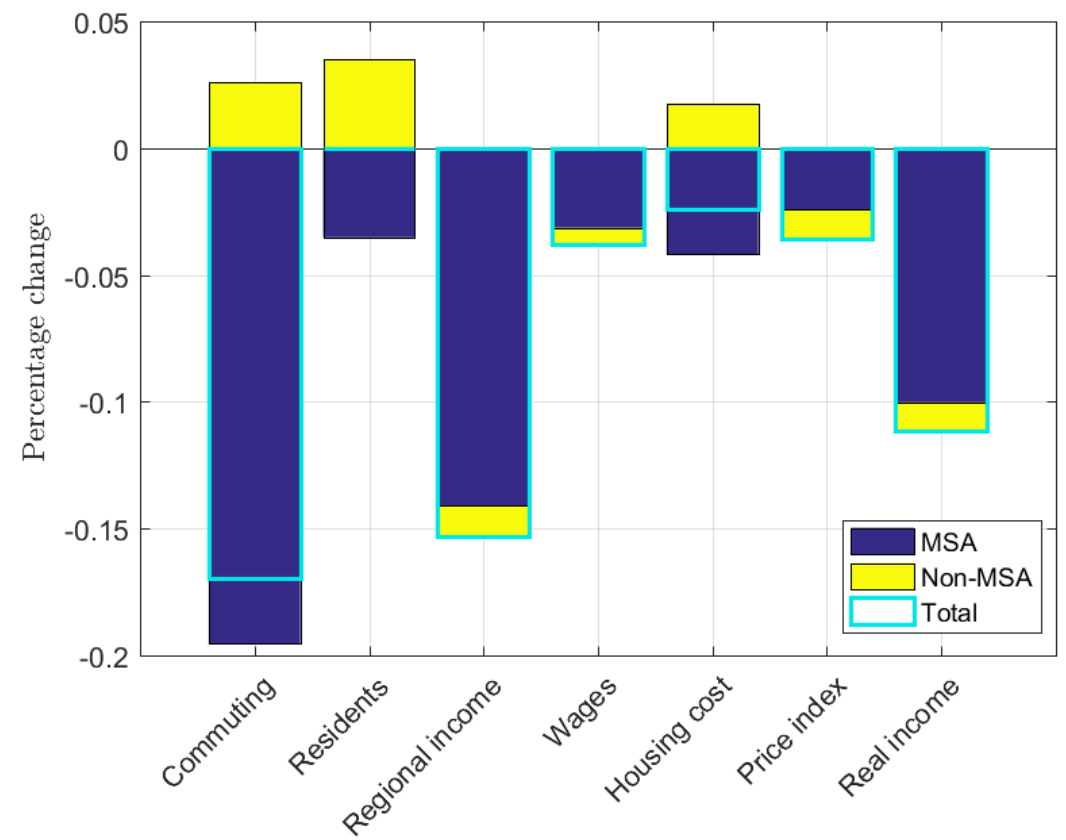

The figure depicts counterfactual changes obtained by setting $\theta=0$. The header 'owners' denotes owneroccupiers. Workers can change place of residence, work and tenure mode. MSAs are defined according to Saiz (2010). County-level counterfactual changes are aggregated using weighted averages based on the distribution of outcomes in the baseline scenario. Changes in commuting are weighted by the number of commuters. Changes in residents, (real) income, prices, and housing costs are weighted by the number of residents. Changes in wages are weighted by the number of workers. 


\section{Center for Regional Economic Development (CRED)}

University of Bern

Schanzeneckstrasse 1

P.O.Box

CH-3001 Bern

Telephone: +41316313711

E-Mail: info@cred.unibe.ch

Website: http://www.cred.unibe.ch

The Center for Regional Economic Development (CRED) is an interdisciplinary hub for the scientific analysis of questions of regional economic development. The Center encompasses an association of scientists dedicated to examining regional development from an economic, geographic and business perspective.

\section{Contact of the authors:}

Yashar Blouri

University of Bern

Schanzeneckstrasse 1

P.O.Box

CH-3001 Bern

Telephone: +41316314792

Email: yashar.blouri@vwi.unibe.ch

Simon Büchler

University of Bern

Schanzeneckstrasse 1

P.O.Box

CH-3001 Bern

Telephone: +41316314792

Email: simon.buechler@vwi.unibe.ch

Olivier Schöni

Laval University

Pavillon Palasis-Prince

2325, rue de la Terrasse

CA-Québec (Québec) G1V 0A6

Telephone: +1 418 656-2131

Email: olivier.schoni@fsa.ulaval.ca

This paper can be downloaded at:

http://www.cred.unibe.ch/forschung/publikationen/cred research papers/index ger.html 